\title{
ARGUMENTACIÓN Y PROCESO: UNA RELACIÓN RELEVANTE EN LA PRÁCTICA JUDICIAL ${ }^{1}$
}

Néstor Leandro Guzmán ${ }^{2}$

GUZMÁN, N. L. Argumentación y proceso: una relación relevante en la práctica judicial. Rev. Ciênc. Juríd. Soc. UNIPAR. Umuarama. v. 18, n. 2, p. 125-162, jul./dez. 2015.

RESUMEN: Las principales teorías de la argumentación identifican los extremos que se relacionan con la práctica judicial. Ellas son enfocadas desde la tensión que se produce entre planteamientos puramente normativos con aquellos que se manifiestan en la actuación cotidiana de los tribunales, que precisamente no se centran en fenómenos normativos exclusivamente. Existen buenas razones para sostener que la coherencia interna del sistema procesal y su aceptación racional, como instrumento válido de resolución de conflictos, dependen del discurso práctico de jueces y abogados, por su complejidad e importancia en cada caso judicial y así establecer niveles de justificación que se apoyan en la autoridad y en la tradición como únicas formas de legitimación del derecho en los estados democráticos.

PALABRAS CLAVE: Teorías de la argumentación. Sistema procesal. Práctica de los abogados y jueces. Legitimidad de la decisión judicial.

\section{INTRODUCCIÓN}

En este trabajo me propongo analizar las ideas centrales de las principales teorías de la argumentación para intentar identificar los extremos que se relacionan, de forma más evidente, con la práctica judicial. Trataré de enfocarlo desde la tensión que se produce entre planteamientos puramente normativos, que siempre corren el riesgo de perder contacto con la realidad, con aquellos que se manifiestan en la actuación cotidiana de los tribunales que precisamente no se centran en fenómenos normativos exclusivamente. Al hacerlo, aduciré buenas razones para sostener, aunque con mucha precaución, que la coherencia interna del sistema procesal y su aceptación racional como instrumento válido de resolución de conflictos depende, en buena medida, del discurso práctico de jueces y abogados.

DOI: https://doi.org/10.25110/rcjs.v18i2.2015.5851

${ }^{1}$ Este trabajo ha obtenido el Primer Premio "Categoría abierta" del Premio Formación Judicial 2007 del Centro de Formación Judicial del Consejo de la Magistratura de la Ciudad Autónoma de Buenos Aires. (Res. CACFJ N ${ }^{\circ}$ 52/07).

${ }^{2}$ Doutorado pela Universidad de Barcelona. 
La idea es entonces analizar el papel que la argumentación ocupa, por su complejidad e importancia, en la experiencia procesal del derecho, antes que dar una definición de cada problema. Asimismo, con la intención de evitar equívocos, convendrá exponer un par de advertencias previas: primero, que no se trata de indicar como se confecciona formal o técnicamente un escrito o una actuación judicial. Parece ingenuo seguir pensando que la práctica del Derecho se puede llevar a cabo sólo dominando una serie, más o menos completa, de normas y modelos procesales. Segunda advertencia: el propósito de las teorías de la argumentación resulta ser más abarcador y complejo, ya que intentan superar el discurso jurídico en términos lógico-normativos pretendiendo ir más allá de niveles de justificación que se apoyan en la autoridad y la tradición como únicas formas de legitimación del derecho en los estados democráticos.

\section{LOS APORTES DE LA ARGUMENTACIÓN JURÍDICAAL MEJORA- MIENTO DEL DISCURSO PRÁCTICO JUDICIAL}

La argumentación jurídica comporta uno de los centros de interés en la actual teoría y filosofía del Derecho. En el intento de hallar razones para estudiar las teorías de la argumentación, resulta relevante subrayar que en el desarrollo de las sociedades democráticas, progresivamente intercomunicadas en lo político, económico y cultural, como en la Grecia clásica, se despierte la necesidad y el interés por la retórica, la argumentación y por la persuasión a través del lenguaje. E inversamente, la causa profunda del desinterés y el olvido en que yació la retórica en épocas pasadas radicarían en la estructura dogmática, autoritaria y coercitiva de aquellas sociedades. ${ }^{3}$

Las teorías de la argumentación jurídica se desarrollaron en Europa tras la Segunda Guerra Mundial con el objetivo de lograr racionalidad y justificación en el proceso de toma de decisiones jurídicas. No sólo se propusieron descifrar como se justifican, sino también cómo se deberían justificar las decisiones jurídicas superando la idea del determinismo metodológico, tan arraigado a los viejos hábitos judiciales, que se resigna a señalar que las decisiones jurídicas no necesitan justificación ya que proceden de una autoridad legítima y resultan de la aplicación de normas generales. ${ }^{4}$

Existen numerosos trabajos que aportan interesantes elementos para representar el proceso real de argumentar jurídicamente y cómo los juristas fundamentan sus actividades. Aquí sólo me ocuparé de algunos de entre ellos. Los

${ }^{3}$ González Bedoya, en el prólogo al "Tratado en la argumentación, La nueva retórica" de Chaim Perelman y Olbrechts-Tyteca, ed. Gredos, Madrid, 1989, pág. 3.

${ }^{4}$ Por decisiones jurídicas entiendo todas aquellas que emanan de los jueces, del Poder Ejecutivo, Legislativo y también de instituciones intermedias en general. 
autores que he seleccionado serán presentados en dos grupos. Por un lado, describiré con algún detalle el contenido de las teorías de Theodor Viehweg, Chaim Perelman y Stephen Toulmin, considerados los precursores de las actuales teorías de la argumentación. Por otro lado, examinaré las ideas principales de Neil Maccormik y Robert Alexy denominadas "teorías estándar de la argumentación". ${ }^{5}$

Sería absurdo, por pretencioso, intentar desarrollar de manera acabada la tesis sobre la argumentación jurídica de cada uno de estos autores. La aspiración es mucho más modesta. Procuraré analizarlas, desde la Tópica de Viehweg hasta las condiciones del argumento práctico racional de Alexy, como partes de una evolución en la búsqueda de satisfacer simultáneamente las exigencias de seguridad jurídica y de aceptabilidad racional de las decisiones jurídicas. Todas ellas, resultan relevantes para encontrar puntos comunes, aunque no definitivos, que permitan reconstruir un modelo de argumentación más acorde a una sociedad democrática y plural.

\section{II.1 LAS IDEAS DE THEODOR VIEHWEG}

Uno de los primeros autores en construir las bases a partir de las cuales se desarrollaron las distintas teorías de la argumentación jurídica fue Viehweg en su obra de referencia, Tópica y Jurisprudencia ${ }^{6}$. En este trabajo, parte de la utilización de los "tópicos", entendidos ya sea como argumentos a extraer de principios generales o decisiones jurisprudenciales que expresan un cierto consenso enfocado a la solución de problemas. Repasa la historia de la "Tópica", desde Aristóteles hasta su utilización más reciente por parte de la doctrina jurídica civilista, teniendo como meta principal crear un nuevo método para la interpretación y aplicación del derecho.?

Viehweg toma de la Tópika de Aristóteles, un tema que ya había sido tratado por la filosofía griega clásica, el viejo arte de disputar distinguiendo lo

\footnotetext{
${ }^{5}$ Muchas de las cuestiones que someto a análisis en este trabajo tienen origen en varios apuntes y escritos que he tomado en el primer ciclo de doctorado que cursé en la Facultad de Derecho de la Universidad de Barcelona en el año 2002. Además, he utilizado especialmente, para la comparación de los distintos autores señalados la obra de Atienza, "Las razones del Derecho, teorías de la argumentación jurídica”, Universidad Autónoma de México, México, 2005, segunda reimpresión. También, la síntesis del mismo autor, "Para una teoría del argumentación jurídica", en Víctor Blanco y Gonzalo Platero (comps.), "Perspectivas actuales del Derecho. Ensayos jurídicos en tiempos de cambio”. ITAM, México, 1991, pág. 87-110.

"Viehweg, "Tópica y Jurisprudencia”. Trad. de Luis Díez-Picazo, ed. Taurus, Madrid, 1964.

${ }^{7}$ Un dato interesante que señala Atienza, es el hecho que las ideas de Viehweg, ("Tópica y Jurisprudencia" publicada por primera vez 1953) guardan un parecido importante con las ideas que sostiene Edward H. Levi, en un obra publicada en 1951 titulada "Anintroduccion to legal reasoning" que desde entonces ha tenido una gran influencia en el ámbito del commonlaw, en "Las razones del Derecho, teorías de la argumentación jurídica” ob. cit. pág. 30.
} 
apodíctico frente a lo que es sólo dialéctico. En este contexto, Aristóteles pretende que el primero sea el campo de la verdad, mientras que el segundo el campo de la dialegueszai, es decir, disputar en el ámbito de lo meramente opinable. De este modo, Viehweg intenta diseñar un método con arreglo al cual, partiendo de proposiciones opinables resulte posible formar silogismos sobre todos los problemas que se puedan plantear evitando las contradicciones, cuando debamos sostener un discurso. Es decir, planteado un problema cualquiera, resulte posible formar conclusiones correctamente para atacar o defender. ${ }^{8}$

Viehweg dedica buena parte de su trabajo en analizar la Tópica como una técnica de pensamiento que se orienta hacia el problema. En este sentido, la Tópica pretende suministrar datos para saber cómo hay que comportarse en una situación semejante a fin de no quedar detenido sin remisión. Es una técnica de pensamiento problemático. Todo problema objetivo y concreto provoca un juego de suscitaciones, que se denomina tópica o arte de la invención, es decir, el arte de tener presentes en cada situación vital las razones que recomiendan y las que desaconsejan dar un determinado paso, tanto las razones a favor como las razones en contra. ${ }^{9}$

En primer lugar, Viehweg se pregunta ¿Qué es un problema? y responde: toda cuestión que, a primera vista, permite más de una respuesta y requiere un entendimiento preliminar. A ese problema se le insertan un conjunto de deducciones para llegar a una contestación: esto es lo que se conoce como sistema. En segundo lugar, plantea el siguiente interrogante: ¿cómo puede acontecer esto en particular?, y dice lo siguiente: cuando se choca cualquiera que sea, con un problema, puede procederse de un modo simple tomando por vía de ensayo, en arbitraria decisión, una serie de puntos de vista más o menos ocasionales buscando de este modo premisas que sean objetivamente adecuadas y que nos puedan llevar a unas consecuencias que nos iluminen. La observación enseña que en la vida diaria casi siempre se procede así. A un procedimiento semejante Viehweg lo denomina, Tópica de primer grado.

Viehweg señala que en este procedimiento deviene inseguridad y esto hace explicable que se trate de buscar auxilio, a través de sencillos repertorios de puntos de vista ya preparados de antemano. En estos casos una investigación ulterior más precisa hace que la orientación conduzca a determinados puntos de vista directivos. De esta manera, se producen catálogos de tópicos; es decir, puntos de vista que gozan de aceptación generalizada aplicables a una determinada rama del saber. A un procedimiento que se sirve de estos catálogos Viehweg, lo denomina, Tópica de segundo grado. ${ }^{10}$

\footnotetext{
${ }^{8}$ Viehweg, "Tópica y Jurisprudencia”, ob. cit., pág 34 y ss.

${ }^{9}$ Viehweg, "Tópica y Jurisprudencia”. ob. cit., pág. 50 y ss.

${ }^{10} \mathrm{Ibid}$., pág 53 y ss.
} 
En este sentido, los tópicos serían premisas posibles para el razonamiento jurídico en cada caso práctico. Ante cada problema, se podrá defender una $\mathrm{u}$ otra decisión mediante todo un conjunto de argumentos aceptables entre los juristas de cada momento, tanto en sí mismos, como argumentos utilizables en derecho, como en su aplicación al caso concreto que se discuta. Esos tópicos o argumentos podrán ser, desde principios del derecho a lugares comunes, evidencias sociales compartidas, precedentes, postulados de justicia hasta las mismas normas jurídicas, etc.

Del pensamiento de Viehweg podemos extraer la idea central que el Derecho no tiene la consideración de sistema, dado que lo decisivo es la solución de los problemas. No se parte de premisas totalmente evidentes, sino que son discutidas para conseguir una solución posible. Para este autor, el Derecho sería un arsinventiendi, un procedimiento de búsqueda de premisas - de Tópicos - y una técnica de pensamiento que enseña a hallar argumentos que son útiles en la justificación de decisiones por gozar de consenso en el conjunto social o en la comunidad de los juristas.

De ahí, que si bien los ordenamientos jurídicos tratan de ordenarse sistemáticamente, sus contendidos no serán producto originariamente de la lógica, sino de la opción entre premisas posibles. La interpretación y aplicación de esos contenidos elevados a normas estará determinada también por una serie de opciones y decisiones, ya que las normas no pueden formular lenguajes comunes e inequívocos.

Cabría señalar dos observaciones, al menos, sobre lo que conviene llamar la atención en las ideas de este autor. Primero, que la tradición de la tópica jurídica puede tener utilidad para el estudio y la práctica del razonamiento jurídico, pero no termina de conformar una base sólida capaz de diseñar una teoría de la argumentación jurídica. En este punto, Atienza señala el nivel de gran generalidad que tienen las ideas de este autor. Sin embargo, sí resulta indudable que la obra de Theodor Viehweg ayudó a que muchos autores comenzaron a repensar la importancia de la argumentación jurídica, el intento de la rehabilitación de la retórica y también de la razón práctica desplazada por la razón teórica siendo su máximo logro haber descubierto un campo fértil para la investigación. ${ }^{11}$

\section{II.2 LA NUEVA RETÓRICA DE CHAIMPERELMAN}

En un sentido similar, Perelman también se retrotrae al pensamiento aristotélico diferenciando entre razonamiento analítico, estudiado por la lógica formal, y un razonamiento dialéctico que intenta conocer los caminos para persuadir y convencer por medio del debate, para criticar las premisas de los adver-

Atienza, "Las razones del Derecho, teorías de la argumentación jurídica", ob. cit. pág 63.

Rev. Ciênc. Juríd. Soc. UNIPAR, v. 18, n. 2, p. 125-162, jul./dez. 2015 
sarios y defender las propias. Este autor, desarrolla su propia teoría denominada "Nueva Retórica", aludiendo al arte de persuadir por medio del discurso. Así, entiende que el Derecho es una manifestación del arte de la retórica, un intento de convencer a partir de tesis que se apoyan en la realidad jurídica y en el derecho vigente en un momento concreto del devenir histórico. ${ }^{12}$

Perelman analiza la persuasión por medio del discurso en el que resulta necesario conocer la tesis del auditorio y el nivel de adhesión a tal tesis. Todo ello, presupone la existencia de un lenguaje común, comprensible por todos los participantes del debate, además de la capacidad del orador para adaptarse al nivel de sus interlocutores. Siguiendo a Viehweg, diferencia entre argumentaciones apodícticas y argumentaciones retóricas. Éstas últimas, se encaminan hacia aquello que nos parece verosímil o probable, aquello respecto de lo cual no existe una certeza absoluta (es el caso de la argumentación jurídica). ${ }^{13}$

Por ese motivo llega a la conclusión, que la lógica jurídica difiere de la lógica formal, ya que ésta trata de mostrar la corrección de las conclusiones y las premisas de las que se parte, siendo las mismas indubitadas, ciertas y seguras. En la lógica jurídica, el camino que se va a seguir es el opuesto: se trata de verificar la aceptabilidad de las premisas a partir de las cuales el juez extraerá unas conclusiones concretas. Además, en la lógica jurídica, no existe correlación entre premisas y conclusiones, pues estas últimas quedan abiertas a múltiples posibilidades. ${ }^{14}$

Ahora bien, Perelman sostiene que en toda argumentación concurren tres conceptos básicos: el Orador, el Discurso y el Auditorio. En el primero de ellos, existen varios participantes (juez, partes, abogados, fiscales, etc.), con posiciones diversas, lo cual exige necesariamente la contradicción puesto que es difícil obtener la avenencia con los argumentos de partida. Por ese motivo, al no haber acuerdo se impone la discusión, la Retórica, donde cada parte defiende su pretensión característica. Orador es interlocutor, quien interviene en un debate o discurso, aportando sus propias ideas o premisas.

Al hablar del Discurso, diferencia entre el discurso deliberativo, dirigido a las asambleas con la intención de obtener la adhesión a cierta tesis, y un discurso epidíptico, en el que se parte de la aceptación previa de los interlocutores de una determinada tesis. El primero trata de convencer; el segundo busca reforzar la opinión del auditorio sobre una cuestión concreta. Uno convence; el otro refuerza el convencimiento previo.

El tercer elemento que señala Perelman es el Auditorio definiéndolo

\footnotetext{
${ }^{12}$ Perelman, "Tratado de la argumentación, La nueva retórica”, ob. cit., pág. 41.

${ }^{13} \mathrm{Ibid}$., pág. 62 y ss.

${ }^{14}$ Perelman, "La lógica jurídica y la nueva retórica”. Traducción de Luis Díez-Picazo, ed. Civitas, Madrid, 1979, pág. 162 y ss.
} 
como el conjunto de destinatarios del discurso concreto sobre el que estamos operando, el conglomerado de inteligencias ante quien se expone el discurso jurídico. Perelman, diferencia el auditorio universal - una ficción sin correlato en los hechos, cuyas conclusiones valen para todos los seres dotados de razón, es decir, con vocación de universalidad, como es el caso del discurso filosófico - del auditorio particular (carente de tal vocación de universalidad, apareciendo dotado de cierto perfil instrumental de cara a la obtención de otras conclusiones que si serán universales).

Llegados a este punto, Perelman procura tomar la argumentación en sentido estricto para señalar, principalmente, que se desarrolla en el terreno de lo meramente plausible. Los argumentos retóricos no tratan de establecer verdades evidentes, pruebas demostrativas, sino de mostrar el carácter razonable, plausible, de una determinada decisión u opinión. De allí que, en la argumentación, y aquí la noción central de su teoría, resulta fundamental la referencia a un auditorio al que se trata de persuadir.

Después de resaltar la necesidad de motivación de toda decisión judicial, para lo cual se remonta al Antiguo Régimen y a la Revolución Francesa, estudia diferentes supuestos de razonamiento: el de los abogados, movido por motivos deontológicos, trata de conseguir el triunfo de la pretensión que ha aceptado defender, invocando para ello normas jurídicas o precedentes, según se trate del sistema continental o anglosajón y el del jurado o el del juez, que es la auténtica culminación de la Lógica jurídica, dado que su función es decir el Derecho.

Este último, ha de conseguir - y aquí otra de las notas claves de su pensamiento - una decisión razonable y aceptable, que no sea ni subjetiva, ni arbitraria. Para lograr tal finalidad el juez utilizará varios instrumentos como la ley, la jurisprudencia, la doctrina y su propio conocimiento del mundo del Derecho. En este sentido, la voluntad del juez se configura a través de un esquema de silogismo, si bien lo que origina el proceso es la discusión de alguno de estos elementos: una premisa mayor, que es la norma aplicable; una premisa menor, determinada por los hechos probados; y una conclusión, consistente en la subsunción de los hechos en la norma jurídica y en la aplicación de las consecuencias que tal norma fija. A todo esto se añade la motivación, inherente a toda decisión judicial, que tiene como objetivo convencer al auditorio de que la decisión no es arbitraria, y la constante búsqueda por el operador jurídico de racionalidad y aceptación de la decisión en el contexto social.

Por otra parte, Perelman diferencia entre un razonamiento judicial, que versa sobre los hechos y otro que versa sobre las cuestiones jurídicas, en sentido estricto. En el primero de los casos, para la mayor parte de los procesos, la valoración del juez se rige por criterios de libertad (no de arbitrariedad), buscando la convicción de cara a evitar toda duda razonable. En relación con el segundo as- 
pecto, lo primero que estudia Perelman es lo concerniente a los conceptos jurídicos indeterminados, cuya interpretación ha de hacer el juzgador casuísticamente (por ejemplo, conceptos como urgencia o necesidad), para pasar luego a los conceptos jurídicos concretos o normativos, en cuyo caso la evolución del Derecho, por vía legislativa o jurisprudencial, ha de adaptar las distintas soluciones a la idea de equidad, tal y como la percibe una sociedad concreta.

En este sentido, el razonamiento judicial debe tener la consistencia precisa para convencer a tres auditorios: las partes, los profesionales del Derecho (incluidas las instancias judiciales superiores) y la opinión pública. La argumentación jurídica se desarrollará a partir de acuerdos previos como son los hechos, las presunciones, los valores y su jerarquía, los lugares comunes y, finalmente, la existencia e interpretación de las reglas de Derecho, con base en los textos legales y en la jurisprudencia. Perelman entiende la relación entre el debate judicial y la lógica jurídica como una elección de las premisas que se encuentran mejor motivadas y que suscitan menos objeciones. De este modo, mientras que el papel de la lógica formal es hacer que la solución sea solidaria con las premisas, en la lógica jurídica es mostrar la aceptabilidad de las premisas.

La tesis de Perelman acota el razonamiento judicial entre dos coordenadas: por un lado, una sistemática como es el respeto al ordenamiento jurídico dado, que ha de ser asumido pero no venerado como algo inmutable. Por otra parte, una consideración de tipo práctico: la búsqueda de soluciones asimiladas por la sociedad que sean justas y razonables. Con esto quiere decir, que lo razonable está ligado al sentido común, a lo que es aceptable en una comunidad dada y no a la idea de verdad. De ahí, que mientras en el mundo de la ciencia sólo una de las tesis en litigio para explicar un fenómeno puede ser verdadera, en materias como el derecho varias propuestas de solución valorativa pueden aparecer como igualmente razonables. Y concluye, señalando que únicamente es no razonable "lo que es inadmisible en una comunidad en un momento dado y lo que la opinión común no puede aceptar, lo que percibe como manifiestamente inadecuado a la situación o contrario a la equidad". ${ }^{15}$

Siendo así, Perelman define el razonamiento práctico como "aquel que justifica una decisión", y el ejemplo prototípico de tal clase de razonamiento sería la motivación de las sentencias por el juez. De ahí, que en la justificación intersubjetiva de las decisiones como razonables, aparece la importancia de la retórica en Perelman. Si la razonabilidad de la decisión no se muestra como evidente o necesaria, sino que ha de ser justificada, argumentada, el instrumento adecuado al efecto será la retórica. "La retórica, tal como la concebimos -dice Perelman- consistirá en un estudio de los medios de argumentación que permiten obtener o acrecentar la adhesión de los espíritus a las tesis que se someten a

\footnotetext{
${ }^{15}$ Perelman, “Ethique et Droit, Bruxelles”, ed. De L'Université de Bruxelles, 1990, pág. 674.
} 
su asentimiento". 16

En definitiva, la lógica jurídica, tal como la entiende este autor, busca la aceptabilidad de las premisas que resulta de la confrontación de medios de prueba, argumentos y valores que aparecen en el seno de un litigio. Ocurre muchas veces que la decisión la dictan consideraciones extra jurídicas y que la motivación que inserta el juicio dentro del sistema de derecho en vigor sólo sobreviene después. La lógica jurídica, especialmente la judicial, que analiza Perelman a través del análisis del razonamiento de los juristas y de las Cortes de Casación, se presenta, en conclusión, no como una lógica formal, sino como una argumentación, que depende de la manera en que los legisladores y los jueces conciben su misión y de la idea que se hacen del derecho y de su funcionamiento en la sociedad. ${ }^{17}$

Por último, resulta interesante la crítica que le hace Atienza en el sentido que Perelman no ofrece, en definitiva, ningún esquema que permita un análisis adecuado de los argumentos jurídicos ni del proceso de argumentación, aunque desde luego, aparecen sugerencias de indudable interés. La retórica tal como es considerada por Perelman cumple ante todo una función de justificación del derecho positivo, presentando como aceptables decisiones que, en realidad, no lo son. Sin embargo, la importancia de la obra de Perelman radica esencialmente en su intento de rehabilitar la razón práctica introduciendo algún tipo de racionalidad en la discusión de cuestiones concernientes a la moral, la política y el derecho. ${ }^{18}$

\section{II.3 LA LÓGICA INFORMAL DE STEPHEN TOULMIN}

Veamos ahora algunas cuestiones de la lógica informal de Toulmin. ${ }^{19}$ En líneas generales, podríamos decir que la especial importancia de las ideas de este autor, así como Viehweg y Perelman, radica en el hecho que su tesis surge como una reacción o intento de dar cuenta de la argumentación a partir de un modelo que no se identifica con la razón deductiva. Su punto de partida es la constatación de que uno de nuestros modos de comportamiento lo constituye la práctica de ra-

\footnotetext{
${ }^{16}$ Perelman, "Tratado de la argumentación, La nueva retórica”, ob. cit., pág 12 y ss.

${ }^{17}$ Perelman, "La lógica jurídica y la nueva retórica”, ob. cit, pág. 232 y ss. En relación con esta idea, el Tribunal Constitucional Alemán expresó, en una decisión del año 1990, el concepto conforme al cual "la interpretación, en particular del derecho constitucional,... (tiene) el carácter de discurso, en el que se hacen valer argumentos a los que se contraponen otros argumentos, debiendo darse finalmente predominio a los mejores argumentos", B VerGE (Siglas Tribunal Constitucional Alemán) 82, 30, pág. 38 ss., citado en Alexy “Teoría del Discurso y Derecho Humanos", ed.Universidad de Externado de Colombia, trad. Luis Villar Borda, Colombia, 1995, pág. 35.

${ }^{18}$ Atienza, "Las razones del Derecho, teorías de la argumentación jurídica”, ob. cit. pág. 101 y ss.

${ }^{19}$ Toulmin, "The Uses of Argument", ed. Cambridge University Press, 1958.
} 
zonar, de dar razones a otros a favor de lo que hacemos, pensamos o decimos. Es decir, aunque exista una gran variedad de usos del lenguaje es posible distinguir una forma instrumental y una forma argumentativa del lenguaje. Este último, supone apoyarse en razones, argumentos o pruebas. ${ }^{20}$

La forma argumentativa del lenguaje tiene lugar, por ejemplo, cuando se plantea una pretensión jurídica. En este sentido, Toulmin entiende que las situaciones y problemas con respecto a los cuales se argumenta pueden ser muy distintos y; en consecuencia, el razonamiento cambia según cada situación particular. Sin embargo, explica este autor, es posible plantear algunas cuestiones que son comunes: una de estas cuestiones es saber cuál es la estructura de los argumentos, esto es de qué elementos se componen los argumentos, que funciones cumplen y cómo se relacionan entre sí. ${ }^{21}$

Toulmin señala entonces que es posible distinguir en la argumentación cuatro elementos: la pretensión, las razones, la garantía y el respaldo. La "pretensión" consiste en lograr que nuestro relato de los hechos sea más creíble que el relato de la parte contraria. Ambos tienen que dar razones serias y relevantes. A su vez, las "razones" no son teorías generales sino los hechos específicos del caso, en una argumentación jurídica típica, por ejemplo, serán cuestiones que integran el supuesto de hecho de la norma aplicable al caso discutido. Por otro lado, "garantías" son los enunciados generales que dependerán del tipo de argumentación que se trate. Por último, el "respaldo" consiste, generalmente, en mostrar que la garantía resultará válida, relevante y con suficiente peso. Todos estos elementos posibilitarán argumentos válidos y concretos. ${ }^{22}$

Ahora bien, Toulmin afirma que el estudio de los argumentos no será completo si no se incluyen las falacias, esto es, las distintas formas de argumentar incorrectamente. De allí, que la fuerza o seriedad de los argumentos, dependerá de cinco tipos diferentes de falacias según surjan: Primero: de una falta de razones, consistente en efectuar una pretensión y argumentar en su favor avanzando en razones cuyo significado es sencillamente equivalente a la pretensión inicial. En segundo lugar, de razones irrelevantes, cuando la prueba que se presenta a su favor no es directamente relevante para la misma; así por ejemplo, cuando se intenta evadir el problema, apelando a la autoridad, la comparación o la fuerza. La tercera falacia, cuando se ofrecen razones que aparecen como correctas, pero inadecuadas para establecer la pretensión especifica en cuestión.

Describe una cuarta falacia, consistente en suposiciones no garantizadas; es decir, que se parta del presupuesto de que es posible pasar de las razones

\footnotetext{
${ }^{20}$ Toulmin- Rieke- Janik, “An Introduction to reasoning”, MacMillan, New York, 1984, pág. 14 y ss. ${ }^{21}$ Toulmin, "El puesto de la razón en la ética", trad. J.F.Ariza, ed. Alianza, Madrid, 1979, pág. 19 y ss.

${ }^{22}$ Toulmin, “The Uses of Argument”, ob. cit., pág. 7 y ss.
} 
a la pretensión sobre la base de una garantía compartida por la mayor parte o por todos los miembros de una comunidad, cuando de hecho la garantía en cuestión no es aceptada. Por último, la quinta falacia, se relaciona con distintos tipos de ambigüedades, cuando una palabra o frase se usa equivocadamente debido a una falta gramatical o una colocación errónea del énfasis cuando se toman similitudes gramaticales o morfológicas entre palabras. Todos estos tipos de falacias provocan que se argumente de forma incorrecta. ${ }^{23}$

La intención de Toulmin está determinada, fundamentalmente, en el hecho de oponerse a una tradición que comienza con Aristóteles y que pretende hacer de la lógica una cuestión formal comparable a la geometría. Por el contrario, Toulmin se propone desplazar del centro de atención de la teoría lógica a la práctica jurídica. No le interesa una "lógica idealizada", sino una lógica operativa o aplicada, considerando como modelo no la geometría sino la jurisprudencia. De la obra de Toulmin, podemos advertir que ha pretendido suministrar un modelo que sea útil para la argumentación en general. En este sentido, señala Atienza que a diferencia de la tópica, aquí estamos frente a una verdadera teoría de la argumentación, con un aparato analítico que ofrece una guía para el ejercicio práctico de la argumentación. ${ }^{24}$

\section{II.4 LA TESIS DE NEIL MACCORMIK}

Concentrémonos ahora en los aspectos más relevantes de la obra de Maccormick que intenta construir una teoría integradora de la argumentación jurídica. La tesis fundamental de este autor se encuentra en la obra titulada "Legal Reasoning and legal theory”. Se trata de una teoría de la argumentación que se propone integrar tanto una idea descriptiva como una finalidad normativa, es decir, una teoría que dé cuenta tanto de los aspectos formales como de los materiales. $^{25}$

En este sentido, Maccormick intenta desarrollar una teoría tanto sobre aspectos deductivos como de la argumentación jurídica, de los aspectos formales y de los materiales y que se sitúe en definitiva, a mitad de camino, entre la teoría del derecho ultra racionalista (como la de Dworkim con su tesis de la existencia de una única respuesta correcta para cada caso) y la irracionalidad (como la de Ross, que sostiene que las decisiones jurídicas son esencialmente arbitrarias, ya que resulta del producto de la voluntad y no de la razón). ${ }^{26}$

\footnotetext{
${ }^{23}$ En un sentido similar los tipos de falacias son analizados por Copi, en "Introducción a la Lógica", Cap. III, "Falacias no formales”, edEudeba, Bs. As. 1962, pág. 81 y ss.

${ }^{24}$ Atienza, "Las razones del Derecho, teorías de la argumentación jurídica”, ob. cit., pág. 84 y ss.

${ }^{25}$ Maccormik, "Legal Reasoning and legal theory", Oxford, University Press, 1978.

${ }^{26}$ Atienza, "Las razones del derecho, teorías de la argumentación jurídica”, ob. cit., pág. 108 y ss.
} 
Parte de la distinción entre contexto de descubrimiento y contexto de justificación, situando a su teoría en el segundo de los ámbitos. El contexto de descubrimiento resulta de la actividad consistente en hallar o enunciar una teoría. En cambio, el contexto de justificación consiste en confrontar una teoría con los hechos a fin de mostrar una validez regida por las reglas del método científico. Ello, trasladado en particular a la argumentación jurídica, permite diferenciar el procedimiento por el cual se llega a establecer una premisa o conclusión y aquel otro procedimiento que consiste en justificar dicha premisa o conclusión.

Por ello, Maccormick señala que la argumentación jurídica cumple, esencialmente una función de justificación. Esta función de justificación está presente en la argumentación explícita que puede hallarse en los sistemas judiciales que tratan de justificar la justicia de acuerdo con el derecho. En este sentido, le asigna un papel trascendente a los conceptos de consistencia y coherencia de las sentencias, que deben tener sentido tanto en relación con el sistema jurídico de que se trate como en relación con el mundo (consecuencias de la decisión).

Una de las críticas que se le pueden formular a Maccormick como también a Perelman, es que sus estudios se centran especialmente en las decisiones de los tribunales superiores, limitando el campo de investigación al ámbito del derecho, quedando fuera de análisis importantes cuestiones de orden fáctico como el problema de la prueba y la función que cumple la argumentación en la determinación de los hechos y la verdad en el proceso judicial. Como explica Taruffo, esta forma de pensar supone una deformación importante: Se olvida que la "verdad" jurídica es aquella que se administra en los tribunales inferiores, especialmente en los tribunales de primera instancia, donde se determinan los hechos y sobre la base de estos se determina el derecho. ${ }^{27}$

\section{II.5 LA TEORÍA DE LA ARGUMENTACIÓN JURÍDICA DE ROBERT ALEXY}

Tomemos ahora una de las tesis que mayor importancia tiene en el mundo jurídico europeo. La teoría de la argumentación jurídica de Robert Alexy ${ }^{28}$. Antes de abordar dicha tarea, me detendré en algunas consideraciones puntuales sobre la ética discursiva de Habermas atento a que la teoría de Alexy viene a significar, por un lado, una sistematización y reinterpretación de la teoría discursiva Habermaniana y; por otro lado, una extensión de esa teoría al campo específico

\footnotetext{
${ }^{27}$ Taruffo, "La prueba de los hechos", ed. Trotta, SEPS, trad. a cargo de Daniel Mendoca y Jordi Ferrer Beltrán, Madrid, 2002, pág. 523.

${ }^{28} \mathrm{Alexy}$, "Teoría de la argumentación jurídica. Teoría del discurso racional como teoría de la fundamentación jurídica". Trad. Manuel Atienza e Isabel Espejo, ed. Centro de Estudios Constitucionales, Madrid, 1989.
} 
del derecho.

Pues bien, Habermas sostiene que la existencia de la sociedad es factible gracias al entendimiento entre los sujetos a través del lenguaje. Con el lenguaje, el individuo participa necesariamente de la perspectiva social, sale "de la lógica egocéntrica". De ahí, que la comunicación lingüística sólo tiene sentido y razón de ser en cuanto orientada al entendimiento con el otro, lo cual hace que quien se comunica no pueda sustraerse a las condiciones de racionalidad inmanentes a la acción comunicativa. Por tanto:

Toda acción lingüística es idealmente una "acción orientada al entendimiento", y quien actúa en sociedad y se comunica, no puede sustraerse a los presupuestos de dicha comunicación. Quien habla aspira a validez general para su emisión, busca que todas las personas reconocidas como interlocutores válidos la admitan como adecuada. De esta manera, el lenguaje resulta la alternativa a la mera violencia entre seres asociales. ${ }^{29}$

Quien realiza un acto de habla está haciendo a sus interlocutores una oferta de entendimiento sobre algo en el mundo objetivo, en la sociedad o en sí mismo, y esa oferta envuelve una pretensión de ser aceptada, de generar acuerdo sobre su corrección a la luz del mundo objetivo, de la sociedad o de la personalidad del sujeto. Y el interlocutor, ante esa oferta, está racionalmente forzado a tomar postura en sentido afirmativo o negativo, admitiendo la validez o cuestionándola. En caso de desacuerdo inicial sobre la validez de la emisión, los interlocutores estarían forzados, por razón de la propia racionalidad inmanente a la comunicación, a buscar el restablecimiento del acuerdo mediante la aportación de razones o argumentos que permitan un nuevo consenso en torno a las mejores razones. ${ }^{30}$

En palabras de Habermas, "con una pretensión de validez un hablante apela a un potencial de razones que, llegado el caso, podría sacar a la palestra en favor de esa pretensión". En última instancia, hablar es comprometerse en la generación de expectativas y entenderse es compartir expectativas, expectativas que, en cuanto compartidas, hacen posible la coordinación social. Así pues:

Toda emisión comunicativa aspira tendencialmente a un entendimiento pleno en torno a un acuerdo de alcance universal. Una emisión comunicativa que responda a la racionalidad última del lenguaje no pretenderá un acuerdo vinculado a razones relativas, o engañosas, o aceptables sólo para algunos. Cuando no ocurre así, cuando a sabiendas se busca un consenso no libre, cuando se manipulan las razones y se instrumentaliza a los interlocutores, se está llevando a cabo

\footnotetext{
${ }^{29}$ Habermas, "Pensamiento postmetafísico", ed. Taurus, Madrid, 1990, pág. 85.

${ }^{30}$ Habermas, "El discurso filosófico de la modernidad", ed. Taurus, Madrid, 1989, pág. 369 y del mismo autor, "Facticidad y validez, Sobre el derecho y el Estado democrático de derecho en términos de teoría del discurso”. ed. Trotta, Madrid, 2001, pág. 296.
} 
una utilización parasitaria del lenguaje. ${ }^{31}$

Para el sujeto racional se sigue una cierta compulsión intelectual a ser congruente con los presupuestos o condiciones de posibilidad de los instrumentos comunicativos de que hace uso para vivir en sociedad. Habermas explica eso que llama también "el fundamento normativo de la comunicación lingüística", diciendo que:

Quien toma parte en un discurso da por sentados "al menos implícitamente", determinados presupuestos, que son los únicos que permiten el acuerdo: así, se llega a la conclusión que los presupuestos de que las proposiciones verdaderas son preferibles a las falsas y que las normas justas (esto es: susceptibles de justificación) son preferibles a las injustas. ${ }^{32}$

Ahora bien, una vez formuladas estas breves nociones sobre las ideas de Habermas examinemos, a continuación, como Alexy las proyecta al campo específico del derecho. El punto de partida de su análisis es considerar al discurso jurídico como un caso especial del discurso práctico general. En ambos casos, se trata de la corrección de enunciados normativos, siendo el discurso jurídico más limitado a causa de una serie de condiciones restrictivas como la sujeción a la ley, la necesaria consideración de los precedentes, el peso de la dogmática elaborada por la ciencia jurídica, y las limitaciones derivadas del ordenamiento procesal. Alexy sostiene, que la argumentación jurídica ha de ser una argumentación racional (el juez ha de actuar sin arbitrariedad) y, si se carece de norma jurídica escrita, la decisión judicial integrará el ordenamiento jurídico según los criterios de la razón práctica y las ideas generales de justicia.

En este sentido, la argumentación jurídica tiene que conseguir una armonización entre los precedentes y el caso concreto, cuya resolución se reclama. Las reglas que el intérprete del Derecho ha de aplicar a un caso particular deben conseguir el equilibrio entre los resultados de casos precedentes y análogos, y las exigencias de lo correcto (el eterno dilema entre justicia y seguridad). De este modo, Alexy procura mostrar la importancia capital que tienen las valoraciones dentro de un sistema jurídico a la hora de aplicar cualquier norma. Dichas valoraciones las agrupa en cuatro categorías diferentes: las valoraciones basadas en consensos existentes de facto; las extraídas del material jurídico consolidado; las derivadas de principios supra positivos; $y$, finalmente, las que surgen de conocimientos empíricos, distintos a los señalados en primer lugar.

Para Alexy, un discurso práctico es racional si satisface las condiciones del argumentar práctico-racional. Estas condiciones pueden ser resumidas en un sistema de reglas del discurso que divide en dos grupos: Reglas que se refieren directamente a la estructura de los argumentos y reglas cuyo objeto inmediato

${ }^{31}$ Habermas, "Pensamiento postmetafísico", ob. cit., pág 84 y ss.

${ }^{32}$ Habermas, “La reconstrucción del materialismo histórico”, ed. Taurus, Madrid, 1981, pág. 179. 
es el procedimiento del discurso. Las reglas del primer grupo, es decir, las que se refieren directamente a la estructura de los argumentos exigen por ejemplo, la no contradicción, la universalidad en el sentido de un uso coherente de los predicados utilizados, la claridad lingüístico-conceptual, la verdad de las premisas empíricas utilizadas, la completitud deductiva de los argumentos, la consideración de las consecuencias, ponderaciones, el intercambio de roles, y el análisis del surgimiento de las convicciones morales. Alexy sostiene, que ninguna teoría de la argumentación práctica racional puede renunciar a ellas.

El segundo grupo de reglas no es de índole monológica, siendo su principal objetivo el aseguramiento de la imparcialidad de la argumentación práctica y; con ello, garantizar el derecho de cada uno a participar en el discurso. Las reglas que sirven a este fin pueden ser llamadas "reglas especificas del discurso". Las más importantes rezan: 1. Todo hablante puede participar en el discurso. 2.1 (a). Todos pueden cuestionar cualquier aserción. (b). Todos pueden introducir cualquier aserción en el discurso. c. (2.2) Todos pueden expresar sus opiniones, deseos y necesidades. 3. Ningún hablante puede ser impedido a través de una coacción dentro o fuera del discurso a ejercer los derechos establecidos en (1) y (2)..$^{33}$

Por otro lado desarrolla las reglas de razón, que señalan lo siguiente: quien afirma algo, no sólo expresa lo que cree, sino que además da a entender que aquello en lo que cree, es lo verdadero y lo correcto. Las reglas de razón aluden a la admisión en el discurso de cualquier interlocutor, así como a la libertad de expresión de los mismos, que no puede verse cercenada por amenazas o coacciones de ningún tipo. Por último presenta las Reglas sobre la carga de la argumentación: quien pretende tratar a una persona de modo distinto que a otra, debe dar una razón para ello. Se trata, en resumidas cuentas, de plasmar el principio de igualdad de trato entre todos los hablantes, sin que en ningún supuesto se produzca discriminación injustificada. ${ }^{34}$

A su vez, Alexy señala que el discurso o debate jurídico puede mostrarse de varias maneras. Algunas veces, de modo institucionalizado (como el de los tribunales de justicia); en otras ocasiones, no sucede así (por ejemplo, una discusión de estudiantes). Unos debates tienen como resultado decisiones vinculantes, mientras que otros carecen de tal elemento. Lo más destacable es que, en todos estos supuestos, se argumenta con arreglo a Derecho y esto implica la vinculación de la argumentación, puesto que se trata de determinar el Derecho vigente.

Alexy añade otro carácter básico de la argumentación jurídica, la exis-

\footnotetext{
${ }^{33}$ Alexy, "El concepto y la validez del derecho", ed. Gedisa, Barcelona, 1997, pág. 137 y ss. ${ }^{34}$ Resulta interesante la relación que Alexy establece entre estas reglas y principios con el estado constitucional democrático, como es el caso de los principios de libertad e igualdad, en "Teoría del discurso y Derechos Humanos", ob. cit., pág. 20.
} 
tencia de ciertas limitaciones. Mientras la forma de debate más libre la constituye, la ciencia jurídica tal libertad resulta limitada en el supuesto del proceso judicial. En este sentido, Alexy afirma que la argumentación tiene sus propios límites en cuanto que no proporciona siempre una única repuesta correcta para cada caso. Se necesita un nuevo procedimiento que cierre esta laguna de racionalidad y que no es otro que el proceso judicial, donde se encontrará una única respuesta correcta de entre las posibles.

Pero, ¿qué es la argumentación jurídica? Alexy la define como el discurso que trata de justificar las decisiones jurídicas. Partiendo de esta definición, diferencia entre justificación interna y justificación externa. La primera tratará de verificar la lógica de la decisión, esto es, determinar si la decisión se ha adoptado siguiendo las premisas que se eligen como fundamentación. Esta justificación descansa sobre el principio de universalidad que, a su vez, sirve de sustento al de justicia formal. ${ }^{35}$

Por otro lado, la justificación externa tiene como objeto el examen de la corrección de las premisas empleadas en la justificación interna, premisas que Alexy clasifica en tres categorías: reglas de Derecho, enunciados empíricos y premisas que no son ni lo uno, ni lo otro. La fundamentación de cada una de ella es diferente, dado que las reglas de Derecho han de respetar los valores y los principios del ordenamiento jurídico, los enunciados empíricos se extraen de los propios métodos empíricos, de las máximas de la razón o de otra serie de reglas, $\mathrm{y}$, finalmente, la categoría restante puede emplear las reglas de la argumentación jurídica.

Alexy agrupa, las reglas y formas de justificación externa en seis clases: ley, dogmática, precedente, razón, empírea y formas especiales de argumentación. Aludiendo a continuación a lo que él denomina "cánones de interpretación", cuya función no se limita a la interpretación en sentido estricto, sino que se aplican también para la fundamentación de normas no positivas o enunciados no normativos. Esos cánones citados son los que siguen: el semántico, genético, histórico, comparativo, sistemático y teleológico. Los dos primeros aludirían a la vinculación de los órganos que deciden con la ley y la voluntad del legislador. Los dos siguientes se referirían a la experiencia pasada y de otros colectivos sociales. El canon sistemático eliminaría las contradicciones del ordenamiento jurídico y el teleológico lleva a la argumentación práctica racional de tipo general.

En este marco, define a la Ciencia del Derecho como la institucionalización estable del discurso práctico bajo la condición de existencia de un ordenamiento jurídico. La misma desempeña variadas funciones, puesto que contribuye: a la fijación de decisiones de modo estable, no inmutable (función de estabilización), a que el ordenamiento jurídico avance (función de progreso), a

\footnotetext{
${ }^{35}$ Alexy, "El concepto y la validez del derecho", ob. cit., pág. 150 y ss.
} 
que no se demuestren de nuevo sus enunciados (función de descarga), a que se verifique el respeto al principio de universalidad (función de control), y a que se elaboren nuevas proposiciones normativas (función heurística). ${ }^{36}$

En suma, Alexy entiende que todas las decisiones jurídicas se obtienen a través de las discusiones, con el respeto a las reglas básicas del discurso general racional. Si éstas se cumplen, la decisión obtenida puede ser considerada como racional. De modo que es el procedimiento lo que garantiza la racionalidad de toda decisión jurídica. Hay que destacar que Alexy no alude al carácter racional absoluto de la decisión, sino a la presunción de racionalidad de la misma, siempre y cuando se respeten las normas del procedimiento a que hemos aludido.

La teoría del discurso es una teoría procedimental de la corrección de las normas. Según ella, una norma es correcta si, y sólo si, puede ser el resultado de un determinado procedimiento, que es el de un discurso práctico racional. Para el carácter de la teoría del discurso como teoría de la justicia tiene especial importancia que el procedimiento del discurso sea un procedimiento de argumentación, y no un procedimiento de decisión. Esta cuestión, la diferencia de las teorías procedimentales de la justicia de la tradición hobbesiana, en las que lo correcto no se busca con argumentos y contra-argumentos, sino que se maximiza la utilidad por medio de la negociación y la decisión. ${ }^{37}$

Conviene advertir en este punto, que contra la tesis sostenida por Alexy se han dado una serie de objeciones al presuponer la existencia de ciertas reglas evidentes, aceptadas unánimemente, cuando la realidad demuestra que eso no es así. Por ejemplo, la idea de veracidad de las afirmaciones de los sujetos que intervienen en el debate. Por otro lado, Alexy desarrolla su teoría sin tener en consideración los criterios éticos que mueven la actuación de los hablantes en el seno del debate, criterios estos que pueden condicionar decisivamente el resultado del mismo. La carencia de una base práctica en su teoría, elaborada sin considerar decisiones jurídicas, hace que carezca de un sustrato fáctico que ampare definitivamente sus ideas.

Oto Weiberger, profesor de la Universidad de Graz y propugnador de la Teoría institucional del derecho, ha polemizado frecuentemente con Alexy. En uno de sus textos, aparecen interesantes objeciones señalando que es indiscutible el significado del discurso y de la corrección de la controversia, tanto para el

\footnotetext{
${ }^{36}$ En un sentido similar, Dworkin nos dice lo siguiente: "cada juez debe verse a si mismo, al sentenciar un nuevo caso, como un eslabón en la compleja cadena de una empresa en las que todas aquellas innumerables sentencias, decisiones, estructuras, convenciones y prácticas son la historia. Su responsabilidad es continuar esa historia hacia el futuro gracias a su labor hoy. Dworkin en el Cap. "Cómo el derecho se parece a la literatura" de laobra titulada "La decisión Judicial, el debate hart-Dworkin, Rodríguez Cesar,, Siglo del Hombre ed, 1998, Bogotá, pág. 167.

${ }^{37}$ Alexy, "La institucionalización de la Justicia”, Colección filosofía, derecho y sociedad, ed. Comares, Granada, 2005, pág. 60 y ss.
} 
desarrollo filosófico y científico como también para el tratamiento de problemas sociales en el espíritu democrático. De ahí, que resulte conveniente disponer de reglas para la organización de la disputa, pero es completamente infundado y en extremo confundidor, suponer que los resultados del discurso (ideal) sean tesis verdaderas o criterios prácticos correctos (fundamentados racionalmente). Los discursos, dice Oto Weiberger, fecundizan el pensamiento, pero no ofrecen ninguna garantía de conocer la verdad o la corrección. ${ }^{38}$

En conclusión, puede resultar, en algún sentido, cuestionable hacer depender "la racionalidad" de las decisiones del proceso que se sigue para tomarlas. Cierto es que el conjunto de normas formales puede aparecer como garantía de dicha racionalidad, pero nunca como causa directa de la misma. La racionalidad dependerá, más bien, de la norma sustantiva aplicable al caso y de la capacidad del hablante, y será siempre relativa pues aparecerá condicionada por otros criterios ajenos a los jurídicos (históricos, políticos, económicos, etc.).

Sin perjuicio de ello, podemos divisar que la argumentación jurídica de Alexy intenta desarrollar la idea de un derecho justo, motivado y razonable, pretendiendo combinar la complejidad de las interacciones humanas y los derechos, con el máximo rigor procedimental. En definitiva, también se puede observar que cada una de las teorías de la argumentación persiguen una clara intención de resolver, desde lo discursivamente posible, los problemas actuales de la sociedad, que han desbordado al positivismo jurídico, más allá de dar una solución metodológica a los problemas de hermenéutica jurídica. En definitiva, todas ellas pretenden abrir un campo para la investigación.

\section{LA ARGUMENTACIÓN JURÍDICA EN LA EXPERIENCIA PROCE- SAL DEL DERECHO}

En este apartado quisiera mostrar de qué modo y en qué medida la argumentación jurídica se manifiesta en el empleo de normas o institutos procesales cuando se los somete a las exigencias de la práctica judicial. Para ello, me detendré en algunos aspectos de la demanda civil, como acto de iniciación del proceso, la problemática de la prueba y la complejidad de elaborar una sentencia judicial. Un planteamiento de esta naturaleza puede ser útil, entre otras cosas, para poner en evidencia la importancia que tiene el problema de cómo argumentar correctamente a fin de mantener la coherencia y la racionalidad discursiva de los distintos sujetos que actúan en el proceso judicial. ${ }^{39}$

\footnotetext{
38 "NormundInstitution", ManzVerlag, Wien, 1988, citado en la Introducción en la obra de Alexy, "Teoría del discurso y Derecho Humanos", ob. cit. pág. 11.

${ }^{39}$ Como explica Larenz, "quién esboza una teoría de la argumentación piensa, sobre todo, en la discusión de las cuestiones jurídicas ante el tribunal, en el despacho profesional y en la literatura. Es obvio,
} 
Ahora bien, el derecho procesal desde una visión instrumental, no regula la argumentación normativo - jurídica como tal, sino que no hace más que asegurar en el aspecto temporal y objetivo el marco institucional para que las partes y el juez puedan interactuar. Las normas relativas al orden del proceso institucionalizan la práctica de la decisión judicial de manera que la sentencia y sus fundamentos puedan entenderse como resultado de un juego argumentativo. A su vez, el profesional del derecho viene disciplinado por un conjunto de reglas que especifican la relevancia que hay que asignar al material a interpretar (por ejemplo, a las palabras, a la intención de las frases, a cuestiones fácticas complejas, etc.), así como por estándares que definen conceptos básicos y establecen las circunstancias procedimentales en la que la interpretación ha de producirse..$^{40}$

Desde esta perspectiva, el proceso judicial comporta un sistema dialéctico donde se procura llegar a la verdad en el marco de una razonable distribución de oportunidades dadas a las partes a lo largo de todo su desarrollo. El debate procesal es y debe ser, necesariamente, un debate ordenado con igualdad de oportunidades de hacer valer los derechos por ambos contendientes. Planteado en estos términos, las normas sustanciales eventualmente aplicables a un caso concreto y aquellas que regulan el debate procesal se vinculan a través de la argumentación. Esta vinculación, que tiene efectos prácticos decisivos, se manifiesta como una actividad intermedia, en la línea de tensión, entre el caso real y las normas que deben regularlo. ${ }^{41}$

Para comprender esta cuestión, comenzaré describiendo con algún detalle las relaciones mutuas que existen entre derecho y proceso, es decir, desde la experiencia procesal del derecho. Las grandes líneas de pensamiento que siguen los autores en respuesta a esta problemática, se concentran en tres posturas principalmente. La primera de ellas, denomina dualista, viene explicada lógicamente por el esfuerzo histórico del derecho procesal por constituirse como ciencia

que el hallazgo del fallo judicial, como también que una opinión logre imponerse en la literatura, se lleva a cabo normalmente por vía del discurso". Larenz, "Metodología del Derecho", ed. Ariel Derecho, Barcelona, 2001, pág. 507.

${ }^{40}$ Resulta interesante el hecho de que Owen Fiss relacione estos principios procedimentales y máximas de interpretación con aquellos que son constitutivos del papel y de la práctica de una administración imparcial de justicia y cuyo fin es asegurar su independencia, el control de la discrecionalidad subjetiva, el respeto por la integridad de las partes en litigio, el que se fundamente por escrito y se dé por escrito la sentencia final. Owen Fiss, "Objectivity and Interpretation", StandfordLawReview 34 (1982) pág.739-763, citado en Habermas, "Facticidad y validez, Sobre el derecho y el Estado democrático de derecho en términos de la teoría del discurso”, ob. cit. pág. 296.

${ }^{41}$ Calamandrei, desarrolla esta cuestión desde el Principio de Dialecticidad donde cada sujeto debe actuar y hablar en el momento preciso, ni antes ni después, del mismo modo que la recitación de un drama cada actor tiene que saber entrar a tiempo para su intervención, o en una partida de ajedrez, en "Derecho Procesal Civil”, Biblioteca de Clásicos del Derecho Procesal Civil, ed. Harla, México, 1998, pág. 249 y ss. 
autónoma. Derecho y Proceso se conciben como dos entes independientes cuyo estudio es tratado en forma autónoma, problemas de fondo de cada caso concreto y problemas exclusivamente de forma o procedimiento. ${ }^{42}$

Frente a esta visión estática que aporta la teoría dualista, se alzan los postulados de las teorías monistas reduciendo los dos términos del problema derecho - proceso a uno sólo, la experiencia procesal del derecho. Es decir, el derecho material no es un prius preexistente al proceso. En él, producto de la dinámica conjunta de la acción y de la jurisdicción, se crea caso por caso el derecho, de tal manera que gráficamente puede decirse que "derecho es lo que aprueban los jueces". Tal afirmación no es pacífica y, no faltan las denominadas teorías intermedias que ofrecen un equilibrio que las lleva a hacer primar, según los temas y las circunstancias, uno de los términos del problema sobre el otro. ${ }^{43}$

Habrá que considerar, entonces, de qué forma incide la práctica de la argumentación en la utilización de normas e instrumentos procesales, precisamente porque tales extremos se funden en la dinámica de la actividad judicial ${ }^{44}$. En esta tarea no se puede olvidar que existen aspectos vedados al investigador, debido a los variados elementos que cada situación particular contiene o que, al menos, podría solamente pronunciar conclusiones relativas. En este contexto, los conceptos que se deben manejar no son puramente doctrinarios y la técnica argumentativa en actuaciones judiciales - como por ejemplo, el acto de una demanda, la fundamentación de la sentencia, la suficiencia técnica de un recurso judicial -, debe ser apreciada objetivamente, teniendo en cuenta las circunstancias concre-

\footnotetext{
${ }^{42}$ Ramos Méndez, “Derecho y Proceso”, ed. Bosch, Barcelona, 1.978, pág. 18. Así, explica el autor, pedagógicamente, existe la necesidad de mantener esta concepción a fin de realizar una explicación adecuada de los temas, además del peso indiscutible de la tradición.

${ }^{43}$ En este orden de ideas, Ver D'ors, "Escritos varios sobre derecho en crisis". Roma-Madrid, Consejo Superior de Investigaciones Científicas, Delegación de Roma, Colección Cuadernos del Instituto Jurídico Español, 1.973, págs. 45 y ss. Serra Domínguez, "Estudios de derecho procesal”, ed. Ariel, Barcelona, 1.969, págs. 63 y ss. Gutierrez de Cabiedes, "Nueva reflexión acerca del concepto de derecho procesal" y "La función del derecho procesal en la vida judicial" en Estudios de Derecho Procesal, Pamplona, ed. Universidad de Navarra, 1.974, págs. 35 y ss y 57 y ss. También, véase Morello, "El ser del proceso en la unidad del orden jurídico", Fundación IUS, La Plata, passin, 1.999, Guerra Filho "Sobre la Dimensión Jusfilosófica del Proceso", RDP №3, ed. Rubinzal - Culzoni, Santa Fe, 1.999 , págs. 575 a 585 . Véase también, Mercader, “El proceso y la unidad del orden jurídico”, J.A. v. III, 1968, pág. 744 y ss.

${ }^{44}$ Para un enfoque desde la Sociología Jurídica, véase, entre otros, Díez-Picazo, "Experiencias Jurídicas y Teoría del Derecho”, ed. Ariel, Barcelona, passin, 1.993 y Carbonier, "Derecho flexible”, ed. Tecnos, Madrid, trad. Diez-Picazo, passin, 1.974.

Berizonce "Las grandes líneas tendenciales del proceso civil a fines del segundo milenio" en "Derecho Procesal Civil Actual”, ed Platense, 1.999, pág. 7 y ss. Claramente el autor, siguiendo la descripción que realizara Satta (La dottrina del Diritto Processuale Civile, Riv. Dir. Proc., 1.992, $n^{\circ} 3$, $p$. 703), dibuja las modernas concepciones del derecho procesal, expresando que el mismo se desplaza desde la ley al juez, o mejor, que la ley y juez son los dos inescindibles momentos de la concreción del derecho, que está en poder de las partes.
}

Rev. Ciênc. Juríd. Soc. UNIPAR, v. 18, n. 2, p. 125-162, jul./dez. 2015 
tas que el caso exhibe.

\section{III.1. LA ARGUMENTACIÓN Y LOS ACTOS DE INICIACIÓN DEL PROCESO JUDICIAL}

Comencemos, como habíamos señalado, por los actos de iniciación del proceso. Generalmente, la labor de los abogados se concentra en tres habilidades básicas y concretas. En primer lugar, necesariamente analizan leyes, opiniones judiciales y situaciones fácticas complejas. En segundo lugar, tienen que ser capaces de resumir con precisión los hechos esenciales del caso para luego, en tercer lugar, pensar en términos tácticos. En este sentido, es necesario combinar la racionalidad discursiva, con la racionalidad estratégica.

Así, desde la instrucción preliminar o pronóstico del caso - actividad extraprocesal y, en ocasiones, procesal, a través de las diligencias preliminares, el abogado, tendrá que investigar los hechos, la veracidad de lo señalado por sus clientes, recolectar y seleccionar el material probatorio no sólo para la mejor defensa de sus intereses, sino también en aras de colaborar con la administración de justicia. Se pone en evidencia que en este estadio, el abogado despliega una actividad similar a la que concreta el juez. Por ello se ha dicho, con acierto, que el abogado es el "primer juez" del asunto. ${ }^{45}$

Es sabido que en la práctica de los tribunales no alcanza con tener razón, sino que hay que saber exponerla. En el proceso civil las alegaciones de las partes, que fundan la pretensión, cobran un papel trascendental. Ellas deben ser aducidas y probadas en tiempo y forma. Ahora bien, el objetivo de una pretensión, se centra en dar razones serias y coherentes para fundamentar que nuestro relato de los hechos y las normas aplicables al caso son las correctas (argumento). Ello, en confrontación con razones opuestas (contra - argumento). De ahí, que tanto en los hechos como en el ámbito del derecho, debe plantearse correctamente la relación jurídica involucrada, la norma en cuestión y su alcance verdadero.

De esta manera, se construyen razones para sostener una tesis determinada. Los argumentos demuestran que la tesis que sostenemos es la verdadera. Para ello, existen dos caminos: fundamentación y refutación. Dependerá de la complejidad del asunto la utilización de uno u otro o ambos. En este sentido, en la fundamentación construimos la tesis relacionando razones en forma sucesiva y una sobre otra para arribar a la conclusión que será definitivamente nuestra tesis. La refutación, en cambio, consiste en demostrar que determinada tesis está apoyada sobre argumentos falsos, ya sea por falacias o vicios propios de la argu-

\footnotetext{
${ }^{45}$ Ver el interesante trabajo de Tessone, nota al fallo, CNCiv., sala D, diciembre 19-996 "Mann, Armando c. Romero, Victor F.", "El abogado y la instrucción preliminar" en LL, Bs. As., t. 1997-E, pág. 151 y ss. También véase, Cueto Rua, “El buen abogado litigante”, LL. Bs. As., 1988-715, № 11 .
} 
mentación. A su vez, la refutación puede atacar la relación sujeto-objeto, o idea-objeto, ya que puede ser un razonamiento correcto pero no parte de la realidad o es inaplicable a ella. ${ }^{46}$

Uno de los errores más comunes en la argumentación de un escrito judicial, son las denominadas falacias, que resultan, como hemos visto en la primera de este trabajo al analizar a Toulmin, de una violación de las reglas de los buenos argumentos. La consecuencia más importante es la pérdida de fuerza o seriedad de la tesis que sostenemos para fundamentar nuestra pretensión. Tomemos dos tipos de falacias, que si bien son generales, sirven para observar cómo construir buenos argumentos, por ejemplo, en un escrito de demanda o contestación de demanda.

La primera de ellas, consiste en extraer conclusiones de una muestra demasiado pequeña. Si un barco desaparece en el Triángulo de las Bermudas y se concluye que el Triángulo de las Bermudas está embrujado, nos encontramos ante una falacia de la generalización a partir de una información incompleta. Es cierto, como expone Weston, que "resulta fácil apreciar este error cuando otros lo comenten, y más difícil de ver si es uno quien lo hace". Otro ejemplo, que brinda Weston, resulta del hecho de que no podemos extraer una conclusión acerca de todo el colectivo de estudiantes de una universidad basada en uno mismo y nuestro compañero de estudios. La regla que se viola es aquella que requiere ejemplos representativos. Es claro que no se puede extraer una conclusión acerca de todo el colectivo de estudiantes de una universidad basándose en los estudiantes que son amigos, aún cuando se tenga un montón de ellos. No se puede generalizar excesivamente a partir del hecho de que usted haya encontrado una causa: otras causas pueden ser más probables. ${ }^{47}$

Una segunda falacia común es el olvido de alternativas, es decir, el hecho de que sólo porque los sucesos A y B estaban correlacionados, no se sigue que A causa B. B podría causar A; alguna otra cosa podría causar ambos, A y B pueden no estar causalmente relacionados, etc. Estas explicaciones alternativas pueden ser olvidadas si aceptamos la primera explicación que tenemos sobre una determinada cuestión. Es común, que en la primera entrevista con el cliente tengamos una versión de los hechos de un modo parcial y necesitemos examinar otras alternativas posibles. La razón de ello, es que el cliente suele presentar sólo una parte de un conjunto de datos que apoyen su afirmación, ocultando las partes de la historia que él considera que lo perjudican. Habrá que esforzarse entonces, en ver las cosas como uno las vería, sucesivamente, si fuera: a) el abogado de la otra parte, y b) el juez. Esto no es fácil, como explica Carrió, "pero no es imposi-

${ }^{46}$ Véase, Falcón "El ejercicio de la abogacia”, ed. Rubinzal Culzoni Editores, Buenos Aires, 2001, pág. 161 y ss.

${ }^{47}$ Weston, “Las claves de la argumentación”, 7 ed. Ariel, Barcelona, 2004, pág 124 y ss. 
ble y dependerá, en buena medida, del temperamento de cada uno". ${ }^{48}$

Por ello, aunque no existe una receta que pueda servir para evitar todas las falacias, el conocimiento de cuáles son y cómo se forman nos puede ayudar. Como regla general Falcón nos dice:

Hay que estar atento a la referencia que se hace de una cosa y otra, porque generalmente representan relaciones a las que se aplican parámetros incorrectos. En las de ambigüedad se debe definir el término, ubicarlo en un contexto, tener más información sobre lo que se quiere comunicar, etc. De manera que si no hemos entendido claramente o sospechamos la existencia de una falacia en una comunicación, antes de discutir, hay que determinar el alcance del mensaje claramente. Para nosotros la tarea es más sencilla pues consiste en observar si existen falacias en nuestro razonamiento para hacerlo más puro, lo que constituye el primer paso del criterio. Es corriente que las personas que dominan hábilmente la argumentación incluyan falacias a propósito con el objeto de lograr sus objetivos y aquí es donde hay que estar especialmente atento. ${ }^{49}$

\section{III.2. LA ARGUMENTACIÓN EN LA PRUEBA JUDICIAL}

Abordemos ahora la cuestión referente al papel que la argumentación ocupa en uno de los aspectos más discutibles de la teoría del proceso que es la determinación de los hechos y el problema de la verdad en el proceso judicial. Procurando alcanzar tal objetivo, examinaré dicha cuestión apoyándome en la obra del profesor de Pavía Michele Taruffo, "La prueba de los hechos" ${ }^{50}$, que fundamentalmente sostiene que no siendo el proceso judicial una empresa científica, no resulta necesario establecer verdades absolutas, siendo suficiente verdades relativas que permitan ofrecer una base razonablemente fundada de la decisión. ${ }^{51}$

Trataré de llamar la atención sobre la importancia que Taruffo le asigna a la cuestión argumentativa, a pesar de la fuerte crítica que realiza a las distintas concepciones que centran la atención en la retórica global del proceso considerando, consecuentemente, el problema de la determinación de la verdad de los hechos como una cuestión irrelevante. En este sentido, argumentaré que la cohe-

\footnotetext{
${ }^{48}$ Carrió, "Cómo estudiar y cómo argumentar un caso", Abeledo Perrot, Buenos Aires, 1999, pág. 70. También resulta interesante la obra de Cueto Rúa, "Estrategias y Tácticas en el proceso civil y comercial", ed. La Ley, Buenos Aires, 2001.

${ }^{49}$ Falcón, "Lógica y justificación del razonamiento probatorio", en "La prueba en el proceso judicial", Segundas Jornadas de Profesores Orientada al análisis crítico y al debate en homenaje al Prof. Oscar Martinez, La Plata, 29 y 30 de septiembre de 2006.

${ }^{50}$ Taruffo, "La prueba de los hechos", ob cit.

${ }^{51}$ Taruffo, apoya sus ideas fundamentalmente en la definición de la verdad como correspondencia de las aserciones referidas a los hechos del mundo empírico, debida en especial aTarski, "La concepción semántica de la verdad y los fundamentos de la semántica”, ed. Valdés Villanueva, Madrid, 1991.
} 
rencia en la reconstrucción de los hechos tiene una importancia en la decisión, pero esto no significa que la verdad dependa en forma absoluta de la coherencia narrativa de su descripción.

Para criticar a las teorías que consideran a la verdad en el proceso civil como un tema que carece de sentido, Michele Taruffo las divide en dos variantes. La primera de ellas, se fundamenta en una interpretación del proceso y de las actividades que en él se desarrollan en clave exclusivamente retórica. Así, todo lo que sucede en el proceso no es más que un juego retórico - persuasivo pudiendo observarse una retórica del proceso dentro de la cual se distinguen retóricas más específicas, como la del abogado, que pretende persuadir al juez de que tiene razón, y la del juez, que al motivar la sentencia intenta persuadir a las partes, a los abogados y a la opinión pública de la bondad de la decisión que ha tomado. ${ }^{52}$

En este sentido, recordemos la noción central de Perelman - que he tratado en la primera parte de este trabajo - que sitúa a la argumentación jurídica en el terreno de lo meramente plausible. Los argumentos retóricos, explicaba este autor, no tratan de establecer verdades evidentes, pruebas demostrativas, sino de mostrar el carácter razonable, plausible, de una determinada decisión u opinión. De ahí, la conclusión, de carácter general, que las teorías sobre la prueba y la determinación de los hechos no serían más que argumentaciones retóricas. ${ }^{53}$

En un contexto metodológico de este tipo, Taruffo señala que el elemento más significativo está representado por las narraciones (stories) de los hechos del caso que los abogados presentan al juez. Los aspectos más importantes de estas narraciones son los referidos a la forma, la claridad, la coherencia y la concordancia con el sentido común. La finalidad de estas historias es persuadir al juez para que adopte su story como fundamento de la decisión. El proceso se centra en las tácticas persuasivas con las que los defensores intentan atraer hacia sus posiciones la decisión final del juez influenciando su adhesión a una u otra story. ${ }^{54}$

En este marco, Taruffo llega a la conclusión que para la retórica (como arte de persuasión), el problema de la verdad de los hechos resulta irrelevante. La retórica pretende, en efecto, conseguir el consenso sobre una tesis cualquiera y conduce a criterios de conveniencia y de eficacia según los cuales es bueno o malo aquello que sirve para alcanzar la finalidad de persuadir a alguien de alguna cosa. Esto es válido también para el proceso, donde la finalidad que persigue el abogado es la de persuadir al juez para que le dé la razón y no la de demostrar

\footnotetext{
${ }^{52}$ Taruffo, "La prueba de los hechos", ob. cit. pág. 48.

${ }^{53}$ Taruffo, explica que Perelman ensayó, en sustento de sus teorías, algunos aspectos del proceso, pero no ha expuesto una concepción retórica global del mismo. "La prueba de los hechos", ob. cit. pág. 49.

${ }^{54}$ Taruffo, "La prueba de los hechos”, ob. cit. pág. 50.
} 
"objetivamente" la verdad de los hechos. Es más, la habilidad y destreza de un abogado se mide en función de la capacidad de persuadir al juez sin importar si la versión de los hechos se corresponde con la realidad.

Por esta razón, la crítica más importante que realiza Taruffo a esta concepción está señalada en el hecho de que la misma se presenta como un modo de dar un ropaje no del todo banal de las tesis del escepticismo de los abogados. Esta concepción ha elaborado además una estrategia defensiva que no carece de interés, según la cual, los conceptos "no retóricos" como el de "determinación" o de "verdad de los hechos" no sería otra cosa que expresiones retóricas dirigidas a disfrazar el hecho de que no existen fenómenos de conocimiento sino sólo fenómenos de persuasión. ${ }^{55}$

La segunda variante que considera la verdad de los hechos como irrelevante surge - explica Taruffo - con los métodos y modelos semióticos de los problemas jurídicos. Esta visión privilegia el aspecto lingüístico del proceso ya que lo considera un ámbito donde se producen diálogos y se elaboran narraciones y es, por tanto, estudiado desde las estructuras lingüísticas y semióticas de esos discursos. Taruffo señala claramente que son diversos los aspectos que afectan directa o indirectamente al problema de la verdad de los hechos en el ámbito de esta corriente metodológica, pero todos convergen en el sentido de hacer de ellos algo irrelevante o no significativo.

En este sentido, la narración de un hecho realizada en el proceso, por ejemplo, por un testigo, no es sustancialmente distinta de la narración de un hecho contenida en una novela; la única diferencia es que la primera pretende ser verdadera, mientras que la segunda no pretende serlo. De ahí, que la debilidad más importante de estas ideas se centraría en el hecho de que pretenden analizar sólo el aspecto argumentativo como la única dimensión significativa del problema. No menos inaceptable, por su parcialidad, - continúa Taruffo - resulta la consiguiente pretensión de reducir el problema de la decisión sobre los hechos a un juego de estructuras semióticas en el que la verdad de los hechos no es siquiera tomada en consideración. ${ }^{56}$

Por su similitud, tengamos presente la crítica más aguda realizada sobre la tesis de Alexy en el sentido que, si bien existe la conveniencia de disponer de reglas para la organización de la disputa, resulta completamente infundado y en extremo confundidor, suponer que los resultados del discurso (ideal) sean tesis verdaderas o criterios prácticos correctos (fundamentados racionalmente). Los discursos, dice Oto Weiberger, fecundizan el pensamiento, pero no ofrecen ninguna garantía de conocer la verdad o la corrección. ${ }^{57}$

\footnotetext{
${ }^{55}$ Taruffo, "La prueba de los hechos", ob. cit. pág. 51.

${ }^{56}$ Taruffo, "La prueba de los hechos", ob. cit. pág.55 y ss.

${ }^{57}$ Citado en la Introducción en la obra de Alexy, "Teoría del discurso y Derecho Humanos", ob. cit.
} 
Ahora bien, es absolutamente cierta la necesidad de partir de la premisa de que el problema tiene sentido, es decir, que éste no se niegue a priori o simplemente se evite dando por descontado que el proceso no puede tender hacia una determinación verdadera de los hechos. Existen buenas razones - señala Taruffo - para adoptar una actitud de optimismo racionalista en el plano metodológico, es decir, como criterio de análisis. La principal razón se fundamenta en el hecho de situar a la determinación verdadera de los hechos entre los objetivos institucionales del proceso, dado que sin esta hipótesis es casi imposible explicar racionalmente en qué consiste la justicia de la decisión. ${ }^{58}$

Llegados a este punto, la coherencia de la reconstrucción de los hechos tiene importancia en la decisión, pero obviamente no significa que deba admitirse que la verdad dependa en forma absoluta de la coherencia narrativa de su descripción. De ahí que, no podemos dudar que narraciones coherentes pueden ser falsas o no tener pretensión alguna de verdad. Es así, que podemos observar una línea coincidente entre la tesis que plantea Taruffo y las consideraciones que Alexy construye para dar una respuesta razonable a esta cuestión sosteniendo que todas las decisiones jurídicas se obtienen a través de las discusiones con el respeto a las reglas básicas del discurso general racional. Es decir, las que se refieren a la estructura de los argumentos y; en especial, la regla de la verdad de las premisas utilizadas. ${ }^{59}$

Si éstas se cumplen, la decisión obtenida puede ser considerada como racional. De modo que sería el procedimiento lo que garantiza la racionalidad de toda decisión jurídica. Hay que destacar que Alexy no alude al carácter racional absoluto de la decisión, sino a la presunción de racionalidad de la misma. Según Alexy, una norma es correcta si, y sólo si, puede ser el resultado de un determinado procedimiento, que es el de un discurso práctico racional. En la teoría del discurso como teoría de la justicia, tiene especial importancia que el procedimiento del discurso sea un procedimiento de argumentación, y no un procedimiento de decisión. Esto la diferencia de las teorías procedimentales de la justicia de la tradición hobbesiana, en las que lo correcto no se busca con argumentos y contra-argumentos, sino que se maximiza la utilidad por medio de la negociación y la decisión. ${ }^{60}$

Una vez presentado este breve panorama sobre el papel que la argumentación ocupa en la determinación de los hechos y el grado de importancia que tiene la verdad en el proceso judicial, me quedan dos observaciones, al menos,

pág. 11.

${ }^{58}$ Taruffo, "La prueba de los hechos", ob. cit. pág. 167 y ss.

${ }^{59} \mathrm{Al}$ respecto, véase las consideraciones efectuadas en la primera parte de este trabajo sobre la Teoría del discurso de Robert Alexy.

${ }^{60} \mathrm{Alexy}$, "La institucionalización de la Justicia”, ob. cit, pág. 60 y ss. 
sobre las que conviene llamar la atención. Por un lado, si estamos de acuerdo que el proceso judicial no es una empresa científica que no requiere establecer verdades absolutas siendo suficiente verdades relativas, la coherencia de la argumentación en la reconstrucción de los hechos tiene una real importancia para lograr una base razonable de la decisión. Por otro lado, ello no significa que deba admitirse que la verdad dependa en forma absoluta de la coherencia narrativa de su descripción, pero no podemos negar que existe una dependencia o vinculación instrumental o de colaboración, de la verdad con la forma u organización de la reconstrucción coherente de los hechos dentro del proceso.

En definitiva, parece claro que de los hechos verdaderos pueden existir distintas interpretaciones escogiendo el juez la narración más coherente de los hechos en cuestión. De esta forma, el criterio de la coherencia de la narración de los hechos puede operar racionalmente como factor de elección entre las distintas versiones de los mismos hechos. Sin embargo, aclara Taruffo, que de este modo la coherencia narrativa opera como criterio diferencial y marginal, aunque en algún caso específico pueda resultar decisivo, porque determina la elección entre stories equivalentes desde el punto de vista de la verdad de los hechos narrados. ${ }^{61}$

\section{3 EL PROBLEMA DE LA JUSTIFICACIÓN DE LAS SENTENCIAS JUDICIALES}

Por último, quisiera examinar algunos aspectos del problema de la justificación de las sentencias judiciales. Como hemos visto en la parte primera de este trabajo, el interés de representar el proceso real de argumentar jurídicamente cobró importancia a partir de la superación, tanto de posturas mecanicistas como de distintas ideas irracionalistas, que reducen la cuestión de la elaboración de una sentencia a una simple remisión a enunciados jurídicos y cuestiones fácticas. Desde suponer que la toma de decisiones del juez representa una especie de "puesta en limpio" o una serie de soluciones tomadas intuitivamente, los que creen que las decisiones jurídicas son puros actos de voluntad, hasta la tesis de Ross que sostiene que las decisiones jurídicas no son, en última instancia, resultado de la razón, sino de la voluntad de los jueces y aplicadores del derecho en general. ${ }^{62}$

Un principio de explicación que ha acompañado la doctrina del silogismo judicial y sus variantes, podría ser que ésta no ha constituido jamás un esquema descriptivo del razonamiento decisorio y tanto menos de la sentencia, sino un modelo descriptivo dirigido a que el juez opere según los cánones de certeza y de necesidad lógica típicos de la deducción silogística. De esta forma, el uso del silogismo resulta conveniente para quien desea fortalecer los valores de legalidad

${ }^{61}$ Taruffo, "La verdad de los hechos", ob. cit. pág. 315.

${ }^{62}$ Ross “Lógica de las normas”, trad. Hierro, ed. Tecnos, Madrid, 1971. 
y certeza de la sentencia y no para quien antepone el valor de la justicia del caso concreto. La argumentación silogística está dirigida a atribuir a la sentencia una apariencia de absoluta necesidad racional para disimular las opciones valorativas del Juez y, por lo tanto, evitar justificarlas. ${ }^{63}$

En este sentido, la aplicación del silogismo en el ámbito judicial resulta excesivamente sintética, atenta a los múltiples factores que se manifiestan en la actividad del juez al momento de elaborar una sentencia. De ahí, que en un estado democrático que pretende una administración de justicia coherente, el acto de motivar las sentencias no deviene únicamente de una exigencia de orden legal, sino de una derivación del ejercicio mismo de la jurisdicción. Por ello, surge la necesidad de analizar, con mayor detenimiento, las nociones de razonamiento $\mathbf{0}$ justificación en la aplicación del derecho.

Michele Taruffo, en su obra La motivazione della sentenza civile intenta una descripción de niveles de justificación. ${ }^{64}$ El objetivo de la teoría de Taruffo, se concentra en determinar la existencia de niveles para el establecimiento de la motivación como discurso justificativo. Sigue la lógica de la justificación partiendo de una fundamental distinción entre contexto decisorio y contexto justificativo. El primero se expresa por la actividad del raciocinio decisorio, teniendo por resultado la decisión. El segundo se expresa por la actividad del raciocinio justificativo, resultando en la motivación.

Es decir, las decisiones de los jueces deben basarse en argumentaciones racionales. De ahí, que para que la motivación sea adecuada, es necesario que la elección sea racional ${ }^{65}$. La elección del magistrado se enmarca, de esta manera, en la determinación de criterios y reglas «guía», y se define por los términos en que se coloca el problema de su racionalidad. La elección racional puede ser entendida como la aplicación correcta de las reglas de decisión. De esta forma, en el contexto decisorio se tiene en cuenta solamente la elección decisoria. Es en el contexto justificativo que se realiza la reformulación de las opciones, con base en una racionalidad justificativa.

La diferencia de contextos y de opciones determina la existencia de dos niveles de justificación donde se evalúa una relación entre juicio y motivación. El primer nivel es el de la estructura lógica, formándose por la descripción de un conjunto de relaciones implicativas entre hecho, norma, calificación de los hechos y decisión final. Entre hecho y norma hay una implicación mutua, de la designación de los hechos a la aplicación de la norma y de la norma individualizada como aplicable a determinados hechos. El segundo nivel corresponde a la justificación de cada enunciado.

${ }^{63}$ Frondisi, "La sentencia civil", ed. Platense, año1994, pág. 23 y ss.

${ }^{64}$ Taruffo. "La Motivazione della Sentenza Civile", ed. Cedam, Padova, 1975.

${ }^{65}$ Alexy “Teoría de la argumentación jurídica”, ob. cit., pág 19. 
Por otro lado, no se puede confundir el concepto de racionalidad de la justificación con el de la logicidad. En ese sentido, surge la pregunta sobre el fundamento de la justificación y de su relación con los juicios de valor. Cabe establecer, de esta forma, una distinción entre racionalidad de la justificación como argumentación, en su aspecto estructural y formal, y racionalidad en el sentido material, es decir, como aceptabilidad de la elección valorativa en que se basa. Se trata de una diferenciación basada en racionalidades internas y externas, que se vuelcan para la coherencia interna y para la coincidencia entre los principios adoptados y los valores asumidos en el ámbito socio-político para el cual se destina la decisión.

En este marco, la motivación de las sentencias constituye un requisito de validez constitucional. La sentencia tiene que ser una derivación razonada del derecho vigente según la expresión desarrollada por la Corte Suprema de la Nación al elaborar la doctrina de las sentencias arbitrarias ${ }^{66} \mathrm{Y}$ una sentencia es derivación razonada del derecho vigente cuando está motivada y fundada. Por lo tanto, la función esencial de la motivación es hacer que el juez justifique expresamente sus propias decisiones posibilitando a las partes, a los abogados, jueces superiores y también a la opinión pública especializada o no, el control externo sobre cómo se ha ejercitado concretamente el poder jurisdiccional. ${ }^{67}$

Así pues, en la fundamentación el juez trata de demostrar que la decisión del caso se ajusta a derecho. Ha de poderse comprender cómo y porqué a los hechos probados se le aplica la norma que rige el caso. Es decir, la sentencia ha de proporcionar a quien la lee una pauta clara que vincule lo decidido con los hechos probados y con la norma en vigor. Si ese hilo conductor no existe, el fallo es arbitrario, porque en lugar de basarse en las circunstancias concretas de la causa, debidamente ponderadas, tiene su raíz nada más que en la pura voluntad del juzgador. ${ }^{68}$

En este contexto, Perelman entiende que ese razonamiento judicial debe tener la consistencia precisa para convencer a tres auditorios: las partes, los profesionales del Derecho (incluidas las instancias judiciales superiores) y la opinión pública. La argumentación jurídica se desarrollará a partir de acuerdos previos como son los hechos, las presunciones, los valores y su jerarquía, los lugares comunes y, finalmente, la existencia e interpretación de las reglas de De-

\footnotetext{
${ }^{66}$ Lorenzetti, “Teoría de la decisión judicial, Fundamentos de derecho”,ed Rubinzal-Culzoni, Bs, As, 2006, pág 211 y ss.

${ }^{67}$ La Corte Suprema de la Provincia de Buenos Aires señala claramente que constituye garantía de los derechos de las partes la obligación judicial de fundar las sentencias de modo que se perciba claramente el itinerario lógico jurídico del que deriva la resolución final, porque la deficiencia en tal sentido se erige en obstáculo al control de legalidad (conf. Ac. 53.976, sent. del 15-IV-97, entre otros precedentes).

${ }^{68}$ Frondisi, "La sentencia civil”, ob. cit., pág. 27 y ss.
} 
recho, con base en los textos legales y jurisprudencia. Resulta interesante como Perelman define a la relación entre el debate judicial y la lógica jurídica como una elección de las premisas que se encuentran mejor motivadas y que suscitan menos objeciones.

A su vez, Alexy sostiene que todas las decisiones jurídicas se obtienen a través de las discusiones con el respeto a las reglas básicas del discurso general racional. Si éstas se cumplen, la decisión obtenida puede ser considerada como racional. De modo que es el procedimiento lo que garantiza la racionalidad de toda decisión jurídica. Hay que destacar, una vez más, que Alexy no alude al carácter racional absoluto de la decisión, sino a la presunción de racionalidad de la misma, siempre y cuando se respeten las normas del procedimiento a que hemos aludido. ${ }^{69}$

La solución del problema parecería poder hallarse en una profundización del esfuerzo en dos sentidos: uno, que fortalezca el carácter de justificación racional que debe necesariamente tener la fundamentación de la sentencia; el otro, tendiente a reforzar el carácter persuasivo de la justificación sobre la base, precisamente, de su racionalidad, de su objetividad, de su apego a la verdad jurídica objetiva y a la realización del valor justicia. La premisa es la racionalidad de la argumentación jurídica contenida en la fundamentación de la sentencia. ${ }^{70}$

Por ello, una sentencia judicial debe ser una decisión doblemente limitada. La primera limitación, resulta del principio de legalidad, que implica que el juez tiene que construir la decisión aplicando el ordenamiento jurídico. Pero como ello no garantiza que no sea una decisión "injusta" o "no razonable", hay un segundo límite a la decisión, límite que viene dado por la racionalidad $\mathbf{0}$ correcta justificación de la misma, y que está en función de las razones dadas en favor de las diferentes opciones que se le plantean al juez a lo largo del proceso de aplicación. Racionalidad no equivale a una absoluta certeza, más bien se relaciona con la idea de aceptar que pueden existir diversas soluciones racionales (no una única solución posible) sobre un concreto caso.

Esta cuestión, tiene una relación directa con el planteo de Taruffo que resalta la necesidad de comprender qué sucede cuando el razonamiento del juez supera los confines de lo que convencionalmente se entiende como derecho, y de individualizar las garantías de racionalidad y de razonabilidad, de credibilidad y de aceptabilidad y de controlabilidad de aquellos numerosos aspectos de la sentencia que no están ni directa ni indirectamente controlados o determinados por el derecho. ${ }^{71}$

Por último, cabría remarcar la necesidad de reconocer un fuerte predo-

\footnotetext{
${ }^{69} \mathrm{Alexy}$, "La institucionalización de la Justicia”, ob. cit, pág. 60 y ss.

${ }^{70}$ Frondisi, "La sentencia civil", ob. cit., pág. 35 y ss.

${ }^{71}$ Taruffo. "La Motivazione della Sentenza Civile”, Padova, ed. Cedam, 1975.
} 
minio del "estilo lógico" que contiene a la sentencia como la conclusión unívoca extraída de premisas ciertas a través de un método formalista de la interpretación. Esta forma de elaborar una decisión, hace que el juez continúe como la boca inanimada de la ley y no como un central protagonista que asuma el papel activo de juzgador. Seguramente, tendrá que ver que todavía tenemos una imagen del juez muy similar al empleo público que se desempeña en funciones importantes pero que resultan esencialmente poco creativas. ${ }^{72}$

\section{A MODO DE CONCLUSIÓN}

Las indicaciones que anteceden no agotan, como es natural, las perspectivas de un tema que tiene tan estrechas conexiones con problemas capitales de filosofía jurídica a los que aquí no podemos siquiera aludir. Fácilmente se comprende que dicha exposición rebasa, con mucho, los límites de este trabajo. Sin perjuicio de ello, el propósito ha sido por mi parte exponer esquemáticamente las ideas centrales de las teorías de la argumentación y trazar conexiones directas entre el lenguaje jurídico, el acto de argumentar y la actividad judicial para señalar la importancia que tiene para la lógica de la administración de justicia contar con un discurso estable y racional del ordenamiento jurídico en su conjunto.

Las teorías sobre la argumentación jurídica persiguen un interés práctico, más que poner de manifiesto verdades evidentes, mostrando el carácter razonable de una decisión obtenida por medio de la argumentación. Es claro también, que no pretenden hallar posiciones originales en el contexto de la moderna metodología jurídica, sino intentar dar respuesta a una mayor exigencia de ajuste de los niveles de justificación de las decisiones jurídicas en una sociedad que aparece como más crítica a los modelos y soluciones que actualmente ofrece el derecho.

Sumado a ello, debemos tener en cuenta que los niveles de desarrollo, el momento histórico y el tipo de régimen político en donde se aplica un sistema jurídico determinado generan concepciones particulares del Derecho. Es diferente en condiciones autoritarias que en democráticas. Y a su vez, el Derecho es diferente que se desenvuelva en una democracia participativa y deliberativa que en una democracia basada en una concepción clásica de representación política. Por ello, el tipo de Estado configura la argumentación y el modelo de derecho,

\footnotetext{
${ }^{72}$ Merryman, "La tradición jurídica Romana-Canónica", ed. Fondo de Cultura Económica, México, 2002, pág. 77.

También puede verse la visión de Damaska que considera esta cuestión como una especie de des-compromiso emocional y como el profesional adquiere, rápidamente, la capacidad de anestesiar su corazón y de tomar -en el rol de funcionario- decisiones que nunca tomaría como individuo., en "Las caras de la justicia y el poder del estado", ed. Jurídica de Chile, Santiago de Chile, Barcelona, México, 2000. pág. 38 y ss.
} 
tal como lo explica Zagrebelsky ${ }^{73}$ o Farrajoli ${ }^{74}$, mostrando como los contextos políticos, económicos, sociales e históricos tiene una alta significación en la argumentación y en la interpretación.

Por otra parte, resulta posible observar una idea común que, en mayor o menor medida, procura comprometer o ligar a la argumentación jurídica con principios y valores constitucionales proscribiendo al determinismo metodológico tan arraigado a los viejos pero actuales hábitos judiciales. La apertura de $l a$ mentalidad social respecto a cuestiones cruciales como la bioética, moral individual o moral social, intereses colectivos, el derecho a la vida, el medio ambiente, etc, hacen que el derecho en su ámbito de aplicación, aparezca desbordado por la realidad necesitando elaborar respuestas equilibradas, rápidas y contundentes.

La necesidad de dar una respuesta tanto a los casos clásicos, o en la terminología de Aarnio ${ }^{75}$, rutinarios, como aquellos más difíciles, en la terminología empleada por Dworkin ${ }^{76}$, hace que la argumentación pase de ser un proceso de simple deducción, a un complejo debate donde hay que tener presente, necesariamente, a los actores, a los hechos y a todo tercero susceptible de ser, no ya sujeto de derecho, sino posible sujeto de argumentación.

En este sentido, el ámbito argumental del derecho se convierte así en un asunto clave para dar respuestas razonadas y aceptables a un gran número de garantías institucionalizadas del estado social. Resulta, en definitiva, lo que Habermas llama juridificación de la sociedad siendo la propia forma jurídica burocrática de tratar administrativamente ciertos problemas, lo que acaba impidiendo una correcta solución. ${ }^{77}$

La ciencia jurídica, expresa Ferragoli, ha dejado de ser simple descripción para ser crítica y proyección de su propio objeto, crítica del derecho inválido aunque vigente cuando se separa de la Constitución. ${ }^{78}$ De allí que, como sugiere Alexy, en la práctica cada decisión se eleva la reivindicación de racionalidad y corrección debiendo intentarse satisfacer esa exigencia, si el sistema jurídico no quiere perder a largo plazo su legitimidad y con ella su aceptación. ${ }^{79}$

Ello nos conduce hacia una idea central: en una administración de justicia de un estado democrático los criterios que se deben utilizar para la resolución de conflictos no son simplemente los legales. El derecho es algo más que normas

\footnotetext{
${ }_{73}$ Zagrebelsky, "El derecho Dúctil, la ley, derechos, justicia”, Madrid, ed. Trotta, 1995, passim.

${ }^{74}$ Ferrajoli. "Derecho y razón. Teoría del garantísmo penal”, Madrid, ed. Trotta, 1997, passim

${ }^{75}$ Aarnio, "Lo racional como razonable", Centro de Estudios Constitucionales, (trad. E. Garzón Valdés y Zimmerling) Madrid, 1991, pág 23.

${ }^{76}$ Dworkin, "Los derechos en serio", (1977), trad. de Guastavino, ed. Ariel, Barcelona, 1984.

${ }^{77}$ Habermas, "Teoría de la acción comunicativa”, ed. Taurus, Madrid, 1987, pág. 532 y ss.

${ }^{78}$ Ferragoli, "Garantismo. Una discusión sobre derecho y democracia", ed. Trotta, Madrid, 2006, pág. 28 y ss.

${ }^{79}$ Alexy, "Teoría del discurso y Derecho Humanos", ob. cit., pág 55.
} 
emitidas por el legislador. El jurista debe emplear otras técnicas para construir criterios coherentes de resolución de conflictos. La importancia práctica de la argumentación en el funcionamiento del derecho implica el abandono de la estricta sumisión a la ley y la aceptación del papel de la razón en la controversia jurídica. ${ }^{80}$

\section{BIBLIOGRAFÍA}

AARNIO, Aulis. Lo racional como razonable: centro de estudios constitucionales. Tradução E. Garzón Valdés y Zimmerling. Madrid: Centro de Estudios Constitucionales, 1991.

ALEXY, Robert. Teoría de la argumentación jurídica: teoría del discurso racional como teoría de la fundamentación jurídica. Tradução Manuel Atienza e Isabel Espejo. Madrid: Centro de Estudios Constitucionales, 1989.

. Teoría del discurso y derecho humanos. Tradução de Luis Villar Borda. Colombia: Universidad de Externado de Colombia, 1995.

. La institucionalización de la justicia. Granada: Comares, 2005. (Colección Filosofía, Derecho Y Sociedad).

. El concepto y la validez del derecho. Barcelona: Gedisa, 1987.

ATIENZA, Manuel. Para una teoría del argumentación jurídica. In: GONZALO PLATERO, VÍCTOR BLANCO Y (Comp.). Perspectivas actuales del derecho: ensayos jurídicos en tiempos de cambio. México: ITAM, 1991.

. Las razones del derecho, teorías de la argumentación jurídica. México: Universidad Autónoma de México, 2005.

BERIZONCE, Roberto. Las grandes líneas tendenciales del proceso civil a fines del segundo milenio en derecho procesal civil actual. Buenos Aires: Platense, La Plata, 1999.

CALAMANDREI, Piero. Derecho procesal civil. México: Harla, 1998. (Biblioteca de Clásicos del Derecho Procesal Civil).

${ }^{80}$ Calsamiglia, "Introducción a la Ciencia Jurídica”, ed. Ariel Derecho, Barcelona, 1986, pág. 106 y ss. 
CALSAMIGLIA, Albert. Introducción a la ciencia jurídica. Barcelona: Ariel Derecho, 1986.

COPI, Irving. Introducción a la Lógica. In: . Falacias no formales. Buenos Aires: Eudeba, 1962.

CARBONIER, Jean. Derecho flexible. Tradução de Diez-Picazo. Madrid: Tecnos, 1974.

CARRIÓ, Genaro. Cómo estudiar y cómo argumentar un caso. Buenos Aires: Abeledo Perrot, 1999.

. Notas sobre derecho y lenguaje. Buenos Aires: Abeledo Perrot, 1990.

CUETO RUA, Julio. EI buen abogado litigante. LL. Bs. As., n. 11, p. 715, 1988.

. Estrategias y tácticas en el proceso civil y comercial. Buenos Aires: La Ley, 2001.

DAMASKA, Mirjan. Las caras de la justicia y el poder del estado. Santiago de Chile; Barcelona, México, Jurídica de Chile, 2000.

D'ORS, Nome. Escritos varios sobre derecho en crisis. Roma: Consejo Superior de Investigaciones Científicas, Delegación de Roma, 1973. (Colección Cuadernos del Instituto Jurídico Español, Roma-Madrid).

DÍEZ-PICAZO, Luis. Experiencias jurídicas y teoría del derecho. Barcelona: Ariel, 1993.

DWORKIN, Rolan. Los derechos en serio. Tradução de Guastavino. Barcelona: Ariel, 1984.

FALCÓN, Enrique. El ejercicio de la abogacía. Buenos Aires: Rubinzal Culzoni, 2001.

. Lógica y justificación del razonamiento probatorio, en La prueba en el proceso judicial: Segundas Jornadas de Profesores Orientada al análisis crítico y al debate en homenaje al Prof. Oscar Martinez, La Plata, 29 y 30 de septiembre de 2006. 
FERRAJOLI, Luigi. Derecho y razón: teoría del garantísmo penal. Madrid: Trota, 1997.

Trotta, 2006.

Garantismo: una discusión sobre derecho y democracia. Barcelona:

FRONDISI, Román. La sentencia civil. Buenos Aires: Platense La Plata, 1994.

GUERRA FILHO. Sobre la dimensión jusfilosófica del proceso. RDP, Santa Fe, Rubinzal - Culzoni, n. 3, 1999.

GUTIERREZ DE CABIEDES. Nueva reflexión acerca del concepto de derecho procesal y La función del derecho procesal en la vida judicial en estudios de derecho procesal. Pomplona: Universidad de Navarra, 1974.

GONZÁLEZ BEDOYA, Jesús. En el prólogo al tratado en la argumentación, la nueva retórica de Chaim Perelman y Olbrechts-Tyteca. Madrid: Gredos, 1989.

HABERMAS, Jürgem. Pensamiento postmetafísico. Madrid: Taurus, 1990.

. El discurso filosófico de la modernidad. Madrid: Taurus,1989.

. Facticidad y validez, Sobre el derecho y el estado democrático de derecho en términos de la teoría del discurso. Madrid: Trotta, 2001.

. La reconstrucción del materialismo histórico. Madrid: Taurus, 1981.

. Teoría de la acción comunicativa. Madrid: Taurus, 1987.

.Teoría y praxis. Madrid: Estudios de Filosofía Social Tecnos, 1987.

LARENZ, Karl. Metodología del derecho. Barcelona: Ariel Derecho, 2001.

LORENZETTI, Ricardo. Teoría de la decisión judicial, fundamentos de derecho. Barcelona: Rubinzal-Culzoni, 2006.

MERCADER, Amilcar. EI proceso y la unidad del orden jurídico. Buenos Aires: J. A. 1968. v. 3.

MERRYMAN, John Henry. La tradición jurídica Romana-Canónica. 
Mexico: Fondo de Cultura Económica, 2002.

MORELLO, Augusto. El ser del proceso en la unidad del orden jurídico. Buenos Aires: Fundación IUS, La Plata, 1999.

PERELMAN, Chaim. Ethique et droit, Bruxelles. Bruxelas: De L'Université de Bruxelles, 1990.

. La lógica jurídica y la nueva retórica. Traducción de Luis DíezPicazo, Madrid: Civitas, 1979.

PERELMAN, OLBRECHTS-TYTECA.Tratado de la argumentación jurídica, La nueva retórica. Madrid: Gredos, 1989.

PRAMOS MÉNDEZ, Francisco. Derecho y proceso. Barcelona: Bosch, 1978.

RODRÍGUEZ, Cesar. La decisión Judicial, el debate Hart-Dworkin. Bogota: Siglo del Hombre, 1998.

ROSS, Alf. Lógica de las normas. Tradução Hierro. Madrid: Tecnos, 1971.

SATTA. La dottrina del diritto processuale civile. Riv. Dir. Proc. Roma, n. 3, 1992.

SERRA DOMÍNGUEZ, Manuel. Estudios de derecho procesal. Barcelona: Ariel, 1969.

STARSKI, Alfred. La concepción semántica de la verdad y los fundamentos de la semántica. Madrid: Valdés Villanueva, 1991.

STON, Anthony. Las claves de la argumentación. 7. ed. Barcelona Ariel, 2004.

TOULMIN, Stephem. The uses of argument. Cambridge University Press, 1958.

. El puesto de la razón en la ética. Tradução J. F. Ariza. Madrid:

Alianza, 1979.

TOULMIN-RIEKE- JANIK. An introduction to reasoning. New York:

MacMillan, 1984. 
TARUFFO, Michele. La motivazione della sentenza civile. Padova: Cedam, 1975 .

. La prueba de los hechos. Tradução a cargo de Daniel Mendoca y

Jordi Ferrer Beltrán. Madrid: Trotta, 2002.

TESSONE, nota al fallo, CNCiv., sala D, diciembre 19-996 "Mann, Armando c. Romero, Victor F.", "El abogado y la instrucción preliminar" en L.L, Bs. As., t. 1997-E.

WEN FISS. Objectivity and interpretation. Standford, Law Review, n. 34. 1982.

WE VIEHWEG, Theodor.Tópica y Jurisprudencia. Tradução de Luis DíezPicazo. Madrid: Taurus, 1964.

ZAGREBELSKY, Gustavo. EI derecho dúctil, la ley, derechos, justicia. Madrid: Trotta, 1995.

\section{ARGUMENTAÇÃO E PROCESSO: UMA RELAÇÃO SIGNIFICATIVA NA PRÁTICA JUDICIAL}

RESUMO: As principais teorias da argumentação identificam os extremos que se relacionam com a prática judicial. Elas são focadas, desde a tensão que se produz, entre as abordagens puramente normativas com aqueles que se manifestam na atuação cotidiana dos tribunais que precisamente não centram em fenômenos exclusivamente normativos. Existem boas razões para sustentar que: a coerência interna do sistema judiciário e sua aceitação racional, como instrumento válido de resolução de conflitos, dependem do discurso prático de juízes e advogados, pela complexidade e importância em cada caso judicial. E assim estabelecer níveis de justificativas que se apoiam na autoridade e na tradição, como única forma de legitimidade do direito nos estados democráticos.

PALAVRAS-CHAVE: Teorias da argumentação. Sistema Judiciário. Prática dos advogados e juízes. Legitimidade da decisão judicial.

\section{ARGUMENT AND PROCESS: A SIGNIFICANT RELATIONSHIP IN LEGAL PRACTICE}

ABSTRACT: The main argumentation theories identify the extremes related to the legal practice. They are focused, from the tension that occurs between the 
purely regulatory approaches and those that manifest themselves in everyday operation of courts, that are precisely not exclusively focused on normative phenomena. There are good reasons to argue that the internal coherence of the legal system and its rational acceptance as a valid tool of conflict resolution depend on the practical discourse of judges and lawyers, as well as the complexity and importance of each court case. And thus, establishing justification levels that rely on authority and tradition as the only form of legitimacy of law in democratic states.

KEYWORDS: Argumentation theories. Legal system. Legitimacy of court decision. Practice of lawyers and judges. 